\title{
Secondary structure of bacteriophage T4 gene 60 mRNA: Implications for translational bypassing
}

\author{
GABRIELLE C. TODD ${ }^{1,2}$ and NILS G. WALTER ${ }^{1,3}$ \\ ${ }^{1}$ Department of Chemistry, University of Michigan, Ann Arbor, Michigan 48109-1055, USA \\ ${ }^{2}$ Program in Chemical Biology, University of Michigan, Ann Arbor, Michigan 48109-1055, USA
}

\begin{abstract}
Translational bypassing is a unique phenomenon of bacteriophage 44 gene $60 \mathrm{mRNA}$ wherein the bacterial ribosome produces a single polypeptide chain from a discontinuous open reading frame (ORF). Upon reaching the 50-nucleotide untranslated region, or coding gap, the ribosome either dissociates or bypasses the interruption to continue translating the remainder of the ORF, generating a subunit of a type II DNA topoisomerase. Mutational and computational analyses have suggested that a compact structure, including a stable hairpin, forms in the coding gap to induce bypassing, yet direct evidence is lacking. Here we have probed the secondary structure of gene $60 \mathrm{mRNA}$ with both $\mathrm{Tb}^{3+}$ ions and the selective $2^{\prime}$-hydroxyl acylation analyzed by primer extension (SHAPE) reagent 1M7 under conditions where bypassing is observed. The resulting experimentally informed secondary structure models strongly support the presence of the predicted coding gap hairpin and highlight the benefits of using $\mathrm{Tb}^{3+}$ as a second, complementary probing reagent. Contrary to several previously proposed models, however, the rest of the coding gap is highly reactive with both probing reagents, suggesting that it forms only a short stem-loop. Mutational analyses coupled with functional assays reveal that two possible base-pairings of the coding gap with other regions of the mRNA are not required for bypassing. Such structural autonomy of the coding gap is consistent with its recently discovered role as a mobile genetic element inserted into gene 60 mRNA to inhibit cleavage by homing endonuclease MobA.
\end{abstract}

Keywords: discontinuous open reading frame; frameshift; bacterial translation; mRNA structure; SHAPE structure probing; terbium-mediated structure probing

\section{INTRODUCTION}

Escherichia coli bacteriophage isolates in the T-even family contain a highly conserved type II DNA topoisomerase whose subunits are encoded by genes 52 and 39 (Hatfull 2008; Cresawn et al. 2011). In contrast, in bacteriophage T4 (T4) the conserved open reading frame (ORF) of gene 39 is disrupted by the insertion of an 1000-bp mobile DNA element. This insertion splits the $\mathrm{N}$-terminal portion of the conserved gene 39 ORF from its C-terminal portion, which is encoded by the new T4 gene 60 (Fig. 1A; Hatfull 2008; Bonocora et al. 2011; Cresawn et al. 2011). The mobile DNA element encodes the homing endonuclease MobA, which catalyzes the transfer of the mobile DNA element between related phage genomes (Edgell et al. 2010; Bonocora et al. 2011). MobA recognizes and cleaves a specific sequence within the genomic DNA of gene 39 (Bonocora et al. 2011) just upstream of the coding region for the highly conserved Toprim motif (Fig. 1B), which coordinates a catalytic $\mathrm{Mg}^{2+}$ in the topoisomerase (Sissi and Palumbo 2009; Laponogov et al. 2010; Bonocora et al.

\footnotetext{
${ }^{3}$ Corresponding author

E-mail nwalter@umich.edu

Article published online ahead of print. Article and publication date are at http://www.rnajournal.org/cgi/doi/10.1261/rna.037291.112.
}

2011). Edges of the cleavage site are degraded by exonucleases, and the cleaved genome is repaired using a mobA-containing genome as a template, resulting in horizontal transfer of the mobA-containing mobile DNA element (Edgell et al. 2010; Bonocora et al. 2011). To prevent self-cleavage, genomes with the mobA genetic element contain an additional short insertion of $50 \mathrm{bp}$ just downstream from the Toprim motif in the newly formed gene 60 . The presence of this additional sequence is necessary and sufficient to completely inhibit MobA cleavage and further homing (Bonocora et al. 2011). Due to the proximity of this short insertion and mobA to the MobA cleavage site, both sequence elements are copied together into cleaved genomes, providing directionality for mobA transfer (Bonocora et al. 2011).

In addition to assisting in MobA-catalyzed homing, the 50-bp insertion into gene 60 triggers an anomalous event at the mRNA level known as translational bypassing (Huang et al. 1988; Weiss et al. 1990; Maldonado and Herr 1998; Herr et al. 2000a,b, 2001; Wills et al. 2008). The insertion is not spliced out of the transcript, yet it is not translated (Fig. 1B; Huang et al. 1988). The untranslated 50 nucleotides (nt), known as the "coding gap," are skipped over by the ribosome in $\approx 50 \%$ of translational events to produce a single polypeptide from two distinct ORFs (referred to hereafter as full- 
A
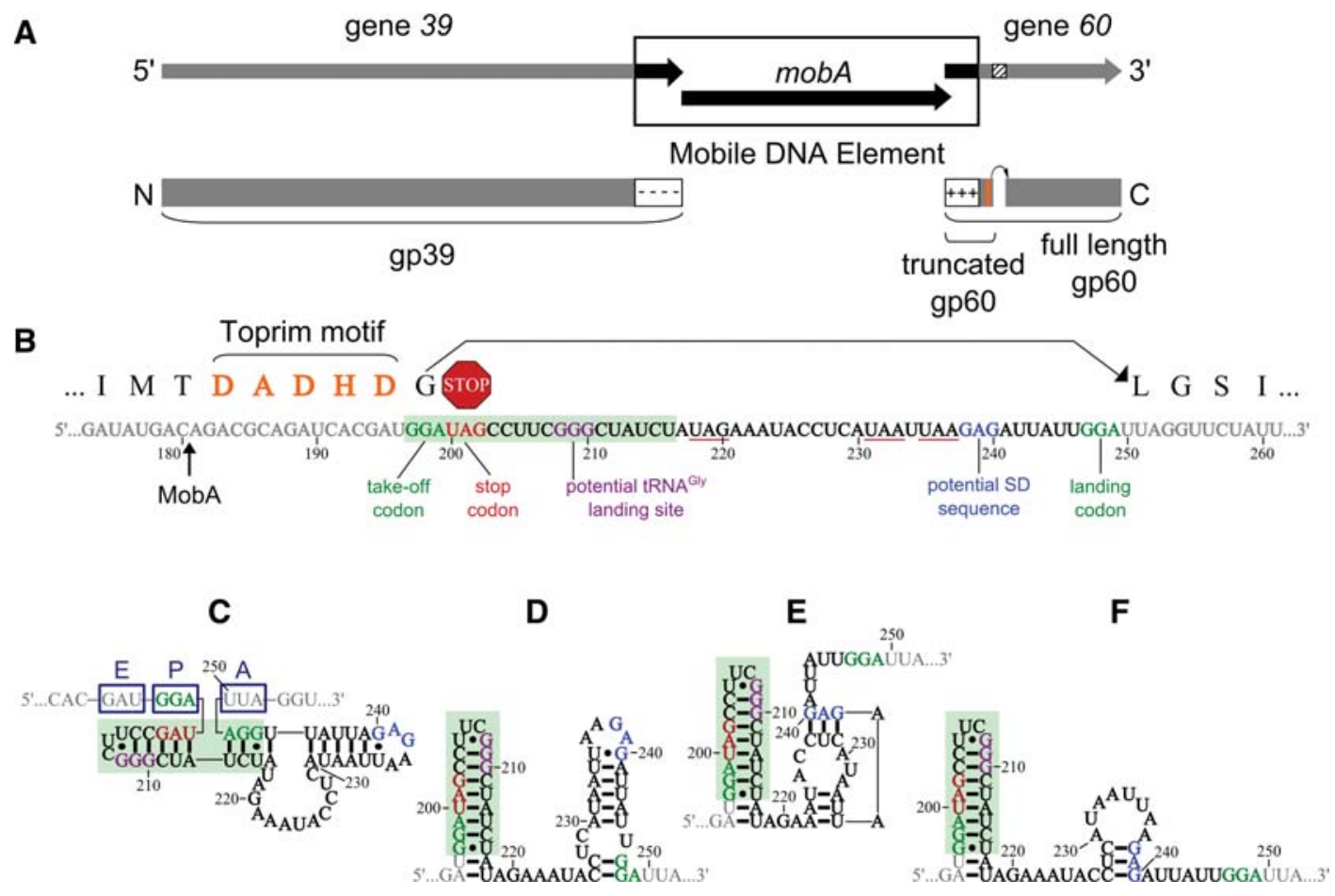

FIGURE 1. Translational bypassing in bacteriophage T4 (T4) gene 60. (A) The conserved T-even gene 39 (gray portion of arrows) was split into two genes by the insertion of a mobile DNA element (black portion of arrows). The N-terminal portion of conserved gp 39 is encoded by T4 gene 39, while the C-terminal portion is now encoded by T4 gene 60 and referred to as gp60. Sequence inserted by the mobile DNA element adds a negatively charged $\mathrm{C}$ terminus and termination signals to gp 39 while adding initiation signals and a positively charged $\mathrm{N}$ terminus to gp60. These signals likely ensure the two protein fragments are translated and may provide a platform for re-association via electrostatic interactions. A second insertion of $50 \mathrm{nt}$ in gene 60 (black striped region) called the coding gap is present in gene $60 \mathrm{mRNA}$ but is skipped over during translation (black curved arrow). Two gp60 products are produced from this transcript: full-length gp60, which has undergone translational bypassing, and truncated gp60 from ribosomes unable to complete bypassing. (B) Sequence of gene 60 mRNA: The translated sequence is shown above gray ORF nucleotides, while coding gap nucleotides are black or colored. Take-off and landing codons (green), stop codons (red), potential SD element (blue), and potential tRNA ${ }^{\text {Gly }}$ landing site (purple) are labeled. Toprim motif amino acids are highlighted in orange (also orange box in A). The site of MobA cleavage is indicated. Potential stop codons in alternative reading frames within the coding gap are underlined in red. Nucleotides highlighted in green compose the hairpin at the $5^{\prime}$ edge of the coding gap. $(C-F)$ Secondary structure models of the coding gap proposed by Huang et al. (1988) and Burke-Aguero et al. (1990) (C) and Le et al. (1993) (D-F; nucleotide colors as in B). Dark blue boxes in $C$ represent the hypothetical location of the ribosomal acyl (A), peptidyl (P), and exit (E) sites.

length gp60); the rest of the time a truncated gp60 is produced due to unsuccessful bypassing (Fig. 1A; Maldonado and Herr 1998; Herr et al. 2000b, 2001). Although originally discovered almost a quarter century ago (Huang et al. 1988), the exact mechanism by which the coding gap induces this unique ribosome bypassing is still unknown (Herr et al. 2000a,b, 2001; Wills et al. 2008; Uzan and Miller 2010). The simplest potential mechanism is an extension of the previously characterized "stop-hopping" (Herr et al. 2000a) or "starvation scanning" (Gallant and Lindsley 1998), wherein either the in-frame stop codon at the $5^{\prime}$ edge of the coding gap or a downstream structure in the mRNA triggers dissociation of the peptidyltRNA ${ }^{\text {Gly }}$ :mRNA interaction or "take-off." The ribosome, still associated with the peptidyl-tRNA ${ }^{\text {Gly }}$, then scans along the transcript until it encounters the Gly codon or "landing site" 50 nt away, at which time the peptidyl-tRNA ${ }^{\text {Gly }}$ rebinds the mRNA and the ribosome continues translation. Consistent with this notion, the coding gap is flanked on either side by matching Gly codons (Huang et al. 1988; Weiss et al.
1990; Maldonado and Herr 1998; Herr et al. 2000a,b, 2001; Bucklin et al. 2005; Wills et al. 2008) and contains a short Shine-Dalgarno (SD)-like element (Fig. 1B) that could align the P-site of the ribosome over the landing codon (Herr et al. 2000a; Wills et al. 2008). This simple mechanism is disfavored, however, by several observations. First, if the ribosome were scanning the coding gap, it would be expected to land most frequently at the Gly codon closest to the take-off site, which in the case of gene 60 mRNA is only $11 \mathrm{nt}$ downstream from the take-off site. This closer Gly codon, however, is never used (Wills et al. 2008). Second, the efficiency of bypassing is 50\% (Maldonado and Herr 1998; Herr et al. 2000b, 2001), which is much higher than the efficiency of stop-hopping (Herr et al. 2000a) and starvation scanning (scans of $22 \mathrm{nt}$ and $40 \mathrm{nt}$ are $20 \%$ and $1 \%$ efficient, respectively) (Gallant and Lindsley 1998). Third, if a scanning mechanism were employed, one would expect that deleting portions of the coding gap to bring the take-off and landing codons closer together would increase efficiency. In contrast, deletions in the coding 
gap decrease efficiency (Weiss et al. 1990; Herr et al. 2000a). Fourth, MobA homing always transfers the complete sequence of the coding gap (Repoila et al. 1994; Bonocora et al. 2011), suggesting that it is needed in its entirety for optimal bypassing. Taken together, these findings suggest that the ribosome is not scanning but is rather completely skipping over the coding gap in gene 60 mRNA.

Given these unique features of gene 60-mediated translational bypassing, several groups have proposed that the coding gap RNA adopts a compact structure to facilitate ribosomal bypassing (Fig. 1C-F; Huang et al. 1988; Burke-Aguero and Hearst 1990; Le et al. 1993; Wills et al. 2008). For example, Huang et al. (1988) proposed a secondary structure in the coding gap of gene $60 \mathrm{mRNA}$ that would place the take-off codon adjacent to the codon following the landing site (Fig. 1C). In this conformation, the ribosome would not need to unwind and/or scan the coding gap region. As an extension of this structural model, Burke-Aguero et al. (1990) proposed that the UGGAU pentanucleotide repeats on either side of the coding gap might affect branch migration in a manner similar to the resolution of a Holliday junction. This would overcome challenges the ribosome may face translating over a discontinuity in the mRNA. In addition to this compact structure, computational predictions of gene $60 \mathrm{mRNA}$ base-pairing by Le et al. (1993) suggest three additional conformations, all of which have folding free energies within $20 \%$ of each other (see Fig. 8D-F, below). Finally, Wills et al. (2008) demonstrated that the ribosome can land on codons upstream of the take-off site. To explain this phenomenon, the investigators suggested that once the peptidyl-tRNA ${ }^{\text {Gly }}$ dissociates from the mRNA, the coding gap region might fold into the A-site of the ribosome, pulling mRNA from both the $5^{\prime}$ and $3^{\prime}$ directions. Common to all of these models is a hairpin containing a tight-turning UUCG tetraloop at the $5^{\prime}$ edge of the coding gap (Fig. 1C-F; Huang et al. 1988; Burke-Aguero and Hearst 1990; Le et al. 1993; Wills et al. 2008).

Extensive mutational analyses have been performed to test various hypotheses about the structural requirements for the coding gap, in particular concerning the presence of the $5^{\prime}$ hairpin (Huang et al. 1988; Weiss et al. 1990; Maldonado and Herr 1998; Herr et al. 2000a,b, 2001; Bucklin et al. 2005; Wills et al. 2008). This hairpin is crucial for bypassing, as mutants destabilizing the stem or extending the loop greatly decrease bypassing efficiency (Weiss et al. 1990; Herr et al. 2000a,b; Wills et al. 2008). Identification of protein products by mass spectrometry from the translation of these hairpin mutants revealed that part of the decrease in efficiency arises from landing at the closer Gly codon 11 nt downstream from the take-off site (Fig. 1B). The stability of the $5^{\prime}$ hairpin thus appears to modulate the relative partitioning of the ribosome into bypassing versus scanning of the coding gap region (Wills et al. 2008). Other features known to be important for bypassing are matching take-off and landing codons (Huang et al. 1988; Weiss et al. 1990; Maldonado and Herr 1998; Herr et al. 2000a,b, 2001; Bucklin et al. 2005; Wills et al.
2008), an in-frame stop codon at the $5^{\prime}$ edge of the coding gap (Weiss et al. 1990; Herr et al. 2000a,b), and the short potential SD-like element just upstream of the landing codon (Fig. 1B; Wills et al. 2008). Finally, bypassing is stimulated by the nascent peptide sequence that lies in the ribosomal exit tunnel as the ribosome approaches the coding gap of gene 60 mRNA (Weiss et al. 1990; Lovett 1994; Larsen et al. 1995; Choi and Brimacombe 1998; Choi et al. 1998; Herr et al. 2000a,b, 2001; Wills et al. 2008).

Despite decades of extensive mutational and computational studies suggesting various secondary structure models for the coding gap (Huang et al. 1988; Burke-Aguero and Hearst 1990; Le et al. 1993; Wills et al. 2008), the structure of gene 60 mRNA has not yet been directly probed. To test the existing structural hypotheses and their relationship to bypassing, we have experimentally assessed the structure of gene 60 mRNA using limited chemical probing with $\mathrm{Tb}^{3+}$ ions and a selective $2^{\prime}$-hydroxyl acylation analyzed by primer extension (SHAPE) reagent under buffer conditions conducive to bypassing, and we find $\mathrm{Tb}^{3+}$ to yield a thermodynamically more stable structural model. As expected, the predicted UUCG-tetraloop hairpin forms at the $5^{\prime}$ edge of the coding gap. Contrary to most previously predicted models, however, we find that the remainder of the coding gap is not significantly structured. Furthermore, mutational analyses coupled with functional assays show that several potential base-pairings between the coding gap and other portions of gene 60 mRNA likely exist in solution but are not required for bypassing. The structurally autonomous nature of the coding gap region is consistent with its role as a collaborative homing partner in the horizontal transfer of genetic material.

\section{RESULTS}

\section{Conditions for translation and bypassing of gene 60 mRNA in vitro}

Prior to structure probing, we sought to determine appropriate buffer conditions under which gene $60 \mathrm{mRNA}$ adopts its functional fold. To this end, we optimized the conditions for observing translational bypassing in a cell-free translation assay (see Materials and Methods). Briefly, mRNA was prepared by in vitro run-off transcription and gel purification. Purified transcripts were added to S30 bacterial cell extract in the presence of ${ }^{35} \mathrm{~S}$-Met, and SDS-PAGE was used to resolve the products resulting from in vitro translation. Figure $2 \mathrm{~A}$ illustrates the various gene $60 \mathrm{mRNA}$ constructs generated for this study (PCR primers used to prepare mutants are listed in Table 1). As expected, for wild-type gene $60 \mathrm{mRNA}$ we observed two predominant bands corresponding in molecular mass to truncated and full-length gp60 (Fig. 2B). Quantification of the bands indicated bypassing levels of $\sim 50 \%$, in accordance with previous reports (Maldonado and Herr 1998; Herr et al. 2000b, 2001). 
A Template

60
$60 \Delta$ gap
$60 \mathrm{~S} 159 \mathrm{C}$
$60 \mathrm{~S} 8 \mathrm{C}$
$60 \Delta$ gap S159C
$60 \Delta$ gap S8C
60 to gap
60 to gap + Cys
60 thru gap
60 thru gap + Cys
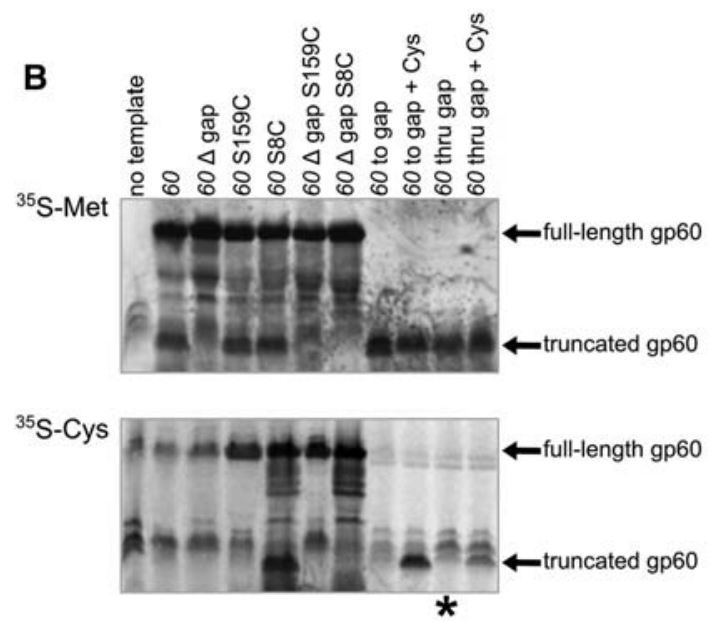

C

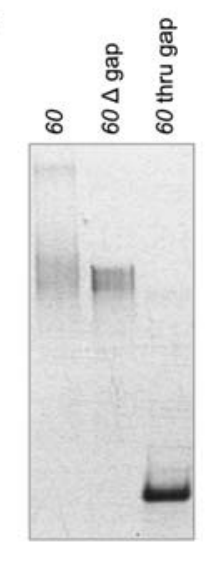

FIGURE 2. In vitro translational bypassing of T4 gene 60 mRNA. (A) Schematic of T4 gene 60 mRNA and mutant transcripts prepared to validate in vitro translation assay. ORF and coding gap regions are depicted by light gray and black rectangles, respectively. Take-off and landing Gly codons are dark gray, while stop codons and positions of added Cys residues are indicated by boxes marked by an $\mathrm{X}$ and striped boxes, respectively. White boxes on either edge of each transcript represent the $5^{\prime}$ and $3^{\prime}$ UTRs, whose sequences are identical for each mutant. Transcripts are not drawn to scale. $(B)$ In vitro translation of each of the transcripts in $A$ in the presence either ${ }^{35} \mathrm{~S}$ Met or ${ }^{35} \mathrm{~S}$-Cys. The asterisk indicates ambiguity of translational bypassing in the gene 60 thru gap + Cys construct (for details, see text). (C) Native gel of the indicated transcripts.

To further support the identity of these two bands, several mutants of gene $60 \mathrm{mRNA}$ were prepared (Fig. 2A). Complete deletion of the 50 -nt coding gap ("60 $\Delta$ gap") generated only a single protein product corresponding to the full-length gp60 band, whereas truncation of gene 60 mRNA after the in-frame stop codon in the coding gap ("60 to gap") produced only truncated gp60 band, both as expected (Fig. 2B). Furthermore, we realized that full-length gp60 contains no natural Cys residues and exploited this feature by mutating Ser8 to Cys as a second way to observe both products of translational bypassing. Alternatively, Ser159, the second-to-last residue of gp60, was mutated to Cys to specifically indicate translation of the entire gene 60 . Both mutations were introduced into the wild-type " 60 " as well as the mutant " $60 \Delta$ gap" mRNAs. We found that " $60 \mathrm{~S} 8 \mathrm{C}$ " mRNA produced two protein products identical to those of wild-type in the presence of either ${ }^{35}$ S-Met or ${ }^{35}$ S-Cys, whereas “60 $\Delta$ gap S8C" mRNA produced only full-length gp60 under both conditions, as expected (Fig. 2B). In contrast, when translated in the presence of
${ }^{35}$ S-Cys, the S159C mutants of both " 60 " and "60 $\Delta$ gap" mRNAs yielded a single band corresponding to full-length gp60 (Fig. 2B), confirming that this band is in fact a translation product of the entire gene 60 ORF. Finally, gene 60 mRNA was truncated after the inframe stop codon at the beginning of the coding gap ("60 to gap"). A Cys residue was incorporated into this construct before the stop codon, just after the take-off Gly, and the proteins resulting from translation in the presence of either ${ }^{35} \mathrm{~S}$-Met or ${ }^{35} \mathrm{~S}$-Cys were identical in size to that of the truncated gp60, further verifying the identity of this band (Fig. 2B). The above results indicate that our assay conditions sufficiently replicate the characteristics of translational bypassing of gene 60 mRNA observed in prior studies (Maldonado and Herr 1998; Herr et al. 2000b, 2001).

We also sought to test the importance of the $3^{\prime}$ portion of gene $60 \mathrm{mRNA}$, as translational bypassing is observed even if the sequence beyond the fifth nucleotide after the coding gap is replaced with a lacZ reporter (Weiss et al. 1990). To test this hypothesis, we generated a mutant of gene 60 that terminates $6 \mathrm{nt}$ (or two amino acids) after the coding gap ("60 thru gap"). The product of bypassing in this shortened construct, however, could not be distinguished from the truncated gp60 band due to their very small difference in molecular weight. The addition of Cys as a third amino acid after the coding gap should only yield a product if translational bypassing has occurred. However, as indicated by the asterisk in Figure $2 \mathrm{~B}$, when translating mutant " 60 thru gap + Cys" in the presence of ${ }^{35} \mathrm{~S}$-Cys, a product of the appropriate size could not reliably be detected over background. This observation suggests that the ribosome requires additional, yet nonspecific, sequence after the coding gap as a landing platform (such as the lacZ reporter used by Weiss et al. 1990).

\section{Gene 60 mRNA adopts an ensemble of structures in solution}

After determining appropriate buffer conditions for probing gene 60 's functional fold(s), we next sought to examine the folding homogeneity of the mRNA. To this end, gene 60 mRNA was prepared in the same buffer used for in vitro translation (S30 buffer), and structural populations were resolved by native gel electrophoresis or by electrophoretic mobility 
TABLE 1. Primers used to generate mutants of gene 60

\begin{tabular}{|c|c|}
\hline Mutant generated & Primer sequences $\left(5^{\prime}-3^{\prime}\right)$ \\
\hline \multirow[t]{2}{*}{ Gene $60 \Delta$ gap } & GATTAGGTTCTATTTATCСТTСТСТGСТCG \\
\hline & САTCGTGATCTGCGTCTGTC \\
\hline \multirow[t]{2}{*}{ Gene 60 to GGA } & TCCATCGTGATCTGCGTCTGTC \\
\hline & TAGTTTACTTTACCACAAGGATGTGG \\
\hline \multirow[t]{2}{*}{ Gene 60 to GGA + Cys } & TCCATCGTGATCTGCGTCTGTC \\
\hline & TGTTAGTTTACTTTACCACAAGGATGTGG \\
\hline \multirow[t]{2}{*}{ Gene 60 thru gap +6 nt } & АССТААТССААТААТСТСТTААТTATGAGG \\
\hline & TAGTTTACTTTACCACAAGGATGTGG \\
\hline \multirow[t]{2}{*}{ Gene 60 thru gap $+6 \mathrm{nt}+$ Cys } & АССТААТССААТААТСТСТTАATTATGAGG \\
\hline & TGTTAGTTTACTTTACCACAAGGATGTGG \\
\hline Ser159Cys & CGTAAAGAATGGATGTGCCAGTAGTTTACTTTACC \\
\hline Ser8Cys & GTAAAAATTGATTGTTCTAGCGTTGATATG \\
\hline \multirow[t]{2}{*}{ Wt SD to CAT SD } & GAGATATACATATGAAATTTGTAAAAATTGATTCTTC \\
\hline & СТTCTTAGAACTTTTCATCAGGAATCC \\
\hline Loop mutant & CGTCGTTCTATTAAGAGTAGCTCAATGAACTATG \\
\hline
\end{tabular}

(Wt) wild-type, (CAT) chloramphenicol acetyl transferase. diester bond $\left(\mathrm{Tb}^{3+}\right)$ or to acylate them (1M7). Modified nucleotides were then identified as stops in primer extension of fluorescently labeled DNA primers. The resulting cDNAs were resolved by $\mathrm{CE}$, and electropherograms were analyzed with the ShapeFinder software (Vasa et al. 2008). Data were then normalized on a scale from zero to approximately one, such that highly reactive, singlestranded nucleotides had an average reactivity of one (Mortimer and Weeks 2008). On this normalized scale, $1 \mathrm{M} 7$ reacted overall slightly more strongly than $\mathrm{Tb}^{3+}$, giving an average reactivity along the mRNA of $\sim 0.43 \pm 0.12$ compared with $\sim 0.35 \pm 0.06$ for $\mathrm{Tb}^{3+}$. Although ad- shift assay (EMSA, Materials and Methods). Refolded, wildtype gene 60 mRNA segregates into a slower migrating EMSA band and two faster migrating, diffuse bands (Fig. $2 \mathrm{C}$ ). The fraction of gene $60 \mathrm{mRNA}$ in each band remained constant as the mRNA concentration was varied from 0 to $500 \mathrm{nM}$ (data not shown), indicating that the slower migrating species is a less compact fold and not the result of multimerization. The existence of multiple conformations is not surprising considering gene 60 's length of $686 \mathrm{nt}$. Accordingly, both the "60 $\Delta$ gap" and much shorter "60 thru gap" mRNAs migrated as more homogeneous folds (Fig. 2C). As the $3^{\prime}$ segment of gene 60 can be replaced with nonspecific sequence while maintaining bypassing (Weiss et al. 1990), our "60 thru gap" mRNA must contain all segments of gene 60 mRNA that are functionally essential for bypassing. Because we could not unequivocally demonstrate bypassing activity in this shortened mRNA, however, we probed the secondary structures of both the full-length "60" and minimal "60 thru gap" mRNAs for comparison.

\section{Secondary structural models of gene 60 mRNA based on $\mathrm{Tb}^{3+}$ and SHAPE probing}

Structure probing of gene $60 \mathrm{mRNA}$ was carried out using the capillary electrophoresis (CE)-based high-throughput analysis method described by Weeks and coworkers (Vasa et al. 2008; Wilkinson et al. 2008; Watts et al. 2009; Low and Weeks 2010). Briefly, in vitro transcribed, gel-purified mRNA was refolded in the same $\mathrm{S} 30$ buffer where we observed bypassing, and probed with either $1 \mathrm{mM} \mathrm{Tb}{ }^{3+}$ ions as described (Walter et al. 2000; Harris and Walter 2003, 2005; Jeong et al. 2003; Harris et al. 2004; Sefcikova et al. 2007a,b) or $2 \mathrm{mM}$ of the SHAPE reagent 1M7 (Mortimer and Weeks 2007; Gherghe et al. 2008, 2010; Watts et al. 2009). These two complementary reagents target accessible 2 '-OH groups, either to deprotonate them and cleave the adjacent phospho- dition of $1 \mathrm{mM} \mathrm{Tb}^{3+}$ to probing reactions altered the ionic strength by $<3 \%$, ions of greater charge density, such as $\mathrm{Tb}^{3+}$, can preferentially stabilize structural elements (including tertiary structures) in an RNA by shielding its negatively charged backbone (Walter et al. 2000; Harris and Walter 2003, 2005; Jeong et al. 2003; Harris et al. 2004; Newby Lambert et al. 2006; Sefcikova et al. 2007b). This feature is a plausible cause for the on average lower overall reactivity of gene 60 mRNA to $\mathrm{Tb}^{3+}$ ions than to the neutral SHAPE reagent. To allow us to directly compare reactivity differences between the two reagents at each nucleotide, the reactivity at each nucleotide position was renormalized such that the average reactivity throughout gene $60 \mathrm{mRNA}$ was set to 0.40 for both reagents.

The pattern of reactivity with gene $60 \mathrm{mRNA}$ nucleotides is generally similar between the two reagents (Fig. 3A), indicating that the data sets capture similar structures. The few regions where the patterns are significantly different are evident from the difference plot of Figure 3B. These differences tend to occur at highly reactive nucleotides. Generally, the range of normalized reactivity for each nucleotide from three independent experiments is less than 0.1 normalized units, as observed for SHAPE reagents previously (Vasa et al. 2008; Watts et al. 2009). For some highly reactive nucleotides, however, the extent of modification varied significantly, leading to higher uncertainty. Narrowly defined values, however, may not be required as long as highly reactive nucleotides are restrained as single-stranded during folding (Vasa et al. 2008).

Average reactivities at each nucleotide position were then used as pseudo-free energy constraints during folding with the Max Expect algorithm in RNAstructure (Reuter and Mathews 2010); the structural models resulting from probing with $\mathrm{Tb}^{3+}$ and 1M7 are presented in Figures 4 and 5, respectively. Nucleotides are color-coded to show their normalized reactivity range; colored dots next to each nucleotide show 


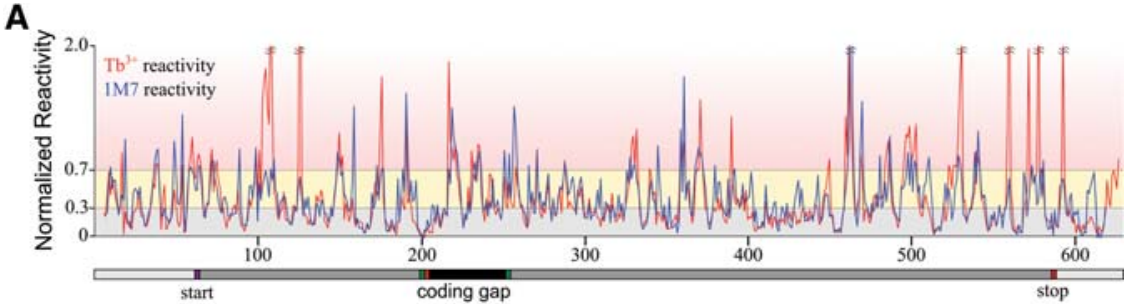

B

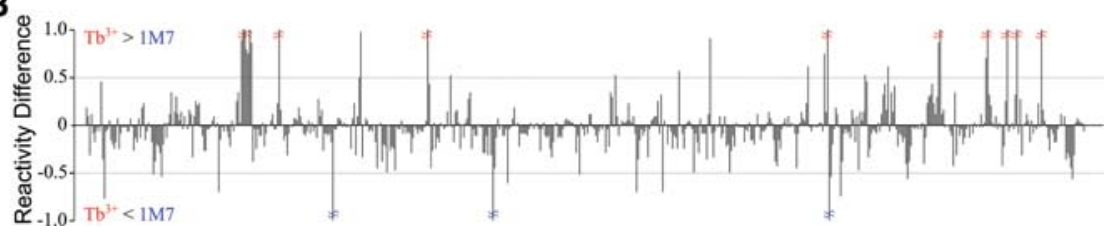

FIGURE 3. Comparison of $\mathrm{Tb}^{3+}$ and $1 \mathrm{M} 7$ reactivity for gene 60 mRNA. (A) Average normalized reactivity of each nucleotide with $\mathrm{Tb}^{3+}$ (red) or $1 \mathrm{M} 7$ (blue). The $x$-axis indicates the nucleotide position in gene $60 \mathrm{mRNA}$, with the gene 60 translation start site and coding gap region indicated. Shading indicates range of nucleotide reactivity: unreactive (gray), moderately reactive (yellow), and highly reactive (red). (B) Difference between average $\mathrm{Tb}^{3+}$ and $1 \mathrm{M} 7$ reactivity at each nucleotide position along gene $60 \mathrm{mRNA}$ ( $x$-axis scale is identical to that in $A$ ).

the normalized reactivity range for the second reagent, as indicated. Overall, the structures fit the data well; highly reactive nucleotides are modeled to reside in single-stranded loops and bulges, whereas unreactive nucleotides are buried in secondary structural elements. The statistical consistency between constraint and prediction was calculated for each model (Materials and Methods), and the results are presented in Table 2. Strikingly, both data sets fit the $\mathrm{Tb}^{3+}$ model slightly better than the 1M7 model. Additionally, the predicted free energy of folding of the $\mathrm{Tb}^{3+}$ model is significantly (by $34 \mathrm{kcal} / \mathrm{mol}$ ) lower than that of the $1 \mathrm{M} 7$ model (Table 2). Interestingly, all highly hit $\mathrm{Tb}^{3+}$ sites are in regions that the $1 \mathrm{M} 7$ model predicts as single-stranded or at the ends of stems (Fig. 5). In contrast, a few examples of strong $1 \mathrm{M} 7$ hits occur in the middle of stable stems in the $\mathrm{Tb}^{3+}$ model (Fig. 4, nucleotides A19, G54, C266). These few strongly hit nucleotides inconsistent with the $\mathrm{Tb}^{3+}$ model likely disfavor corresponding stems during the folding calculations, leading to the significantly higher free energy of the 1M7 model. At thermodynamic equilibrium in solution, this difference is expected to lead to a several orders-of-magnitude preference for the $\mathrm{Tb}^{3+}$ over the $1 \mathrm{M} 7$ fold. Finally, a minimal free energy structure generated based on the average of the normalized $\mathrm{Tb}^{3+}$ and $1 \mathrm{M} 7$ reactivities did not significantly differ from that generated based on the $\mathrm{Tb}^{3+}$ data alone (data not shown). Based on these results, we conclude that the $\mathrm{Tb}^{3+}$ model is the favored conformation of gene 60 mRNA in solution.

\section{A structural model of the minimal "60 thru gap" mRNA resembles that of the full-length mRNA}

We noticed that in both of our experimentally derived fulllength gene $60 \mathrm{mRNA}$ structural models, the $5^{\prime}$ and $3^{\prime}$ portions of the mRNA fold relatively independently of one another (i.e., tend to form local structure elements such as long stem-loops) (Figs. 4, 5). This feature is functionally supported by the fact that the entire $3^{\prime}$ portion of gene 60 mRNA can be replaced by a lacZ reporter without disrupting translational bypassing (Huang et al. 1988; Weiss et al. 1990). Thus, any structural features critical for translational bypassing must not require a specific sequence in the $3^{\prime}$ end of gene $60 \mathrm{mRNA}$. Furthermore, the $5^{\prime}$ portion of gene 60 known to be involved in bypassing (embodied in the "60 thru gap" mRNA) migrates as a single homogeneous population during EMSA (Fig. 2C), indicating it is a good candidate for structure probing.

The minimal gene "60 thru gap" mRNA was thus probed with both $\mathrm{Tb}^{3+}$ and SHAPE reagents. We found extensive similarities in reactivity between the minimal and full-length gene 60 mRNAs (Fig. 6A,C). A structural model of the "60 thru gap" mRNA derived from the $\mathrm{Tb}^{3+}$-mediated probing data is shown in Figure 7 (1M7 data overlaid; structure not shown), and structural features in common between full-length and truncated gene 60 mRNA probed with $\mathrm{Tb}^{3+}$ are shaded. The extensive similarities between the truncated and fulllength models for both probing reagents validate the $5^{\prime}$ portions of our full-length gene 60 mRNA models (Figs. 4, 5). They also suggest that the majority of the heterogeneity in full-length mRNA on the native gel (Fig. 2C) arises from multiple conformations in the $3^{\prime}$ end that do not greatly influence the structure of the functional $5^{\prime}$ portion.

A difference plot between the reactivities of the truncated and full-length mRNAs emphasizes the similarity between the two structures (Fig. 6B,D). For almost all nucleotides, the difference in reactivity is well below 0.5 normalized units. Upon $\mathrm{Tb}^{3+}$ probing, U126 shows the most extreme difference between the full-length and gene " 60 thru gap" mRNAs. This nucleotide is very reactive in full-length, while only modestly reactive in the truncated mRNA. This variation could be because this nucleotide becomes involved in more local interactions and/or loses a metal binding site in the truncated form. The very $3^{\prime}$ end of the coding gap shows some minor differences between the two mRNAs, but the disparity in reactivity is likely due to changes in local environment caused by loss of the immediate downstream sequence in the truncated mRNA. Notably, the differences between the reactivities of the truncated and full-length mRNAs are more pronounced upon 1M7 probing, again consistent with the notion that $\mathrm{Tb}^{3+}$ better stabilizes the consensus structure of the conformational ensembles that are probed in both mRNAs. 


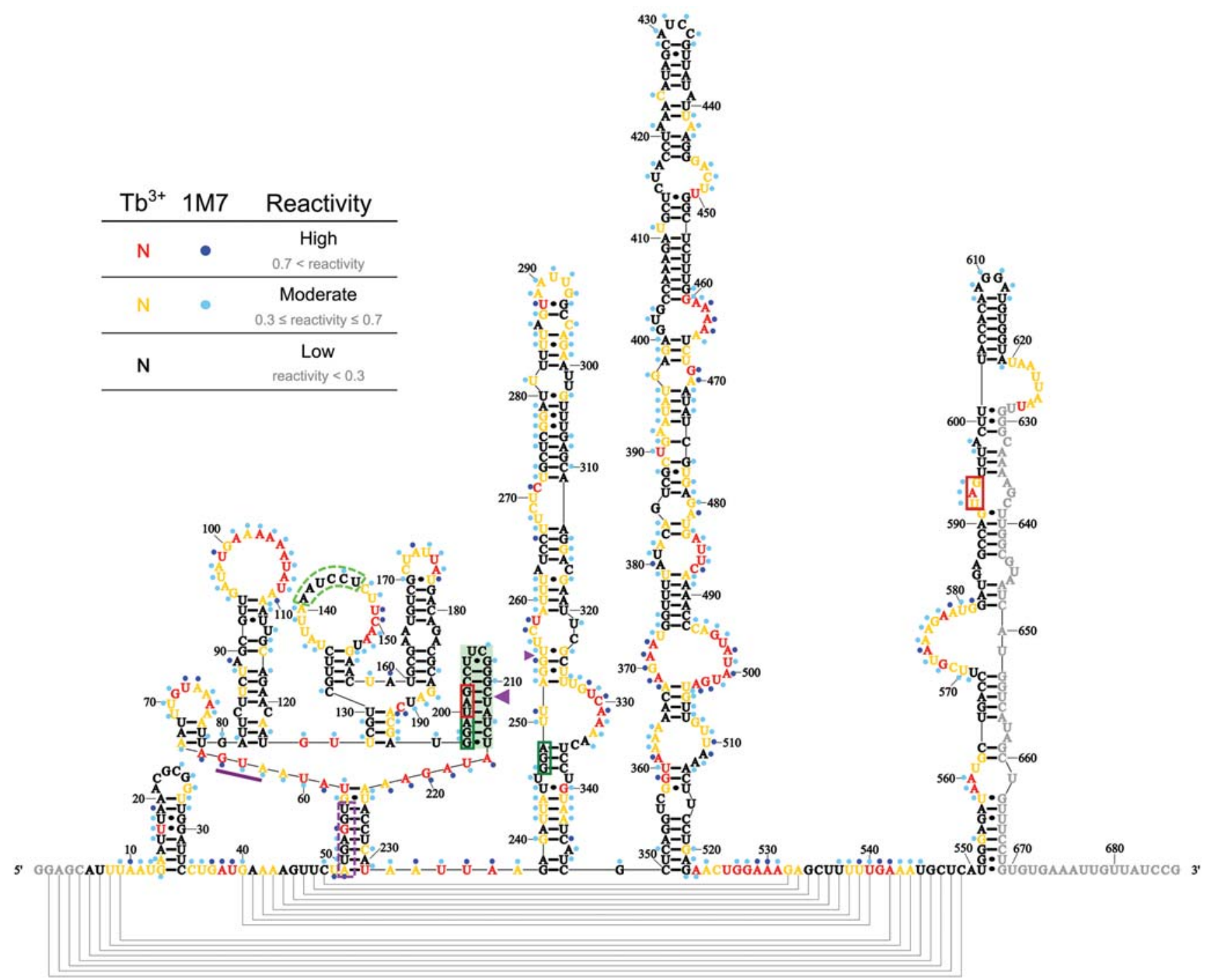

FIGURE 4. Secondary structure model of gene 60 mRNA generated from $\mathrm{Tb}^{3+}$ data. The mRNA is rendered from $5^{\prime}$ to $3^{\prime}$ from left to right. Nucleotides are color-coded based on their reactivity range: low reactivity (black), moderate reactivity (orange), high reactivity (red). Colored circles indicate nucleotides that are moderately (light blue) or highly (dark blue) reactive with the 1M7 SHAPE reagent. The gene 60 start codon is underlined in purple, the take-off and landing codons are boxed in green, and stop codons are boxed in red. The hairpin at the $5^{\prime}$ edge of the coding gap is shaded in green. Large and small purple triangles represent major and minor AMV reverse transcriptase stops, respectively, as determined by Huang et al. (1988). The SD of gene 60 mRNA and protected loop nucleotides (for details, see text) are enclosed in dashed purple and light green boxes, respectively.

\section{A $5^{\prime}$ hairpin and a short stem-loop are the only predominant features in the coding gap}

We next asked which of the multiple compact structures of the coding gap region previously suggested to induce translational bypassing on gene 60 mRNA (Fig. 1C-F; Huang et al. 1988; Burke-Aguero and Hearst 1990; Le et al. 1993; Wills et al. 2008) is most consistent with our experimentally validated secondary structure. Common to all of these models is a tight-turning hairpin at the $5^{\prime}$ edge of the coding gap (Weiss et al. 1990; Herr et al. 2000a,b; Wills et al. 2008). Consistent with this predicted hairpin, we find nucleotides 197-216 all highly protected from both reagents, with an average reactivity of $0.11 \pm 0.07$ for $\mathrm{Tb}^{3+}$ and $0.18 \pm 0.12$ for $1 \mathrm{M} 7$ (Fig. 8A). Low reactivity includes the 2 -hydroxyls of the loop region of the hairpin, which is expected given that the tight turn of UUCG-loops is generated by intramolecular hydrogen bonding of the 2'-hydroxyls of the first three loop nucleotides (Ennifar et al. 2000). Based on our reactivity data, it appears that the stem only extends through the take-off Gly codon, despite the potential for two additional Watson-Crick base pairs to form (Fig. 8B-F). In addition to extensive mutational analyses (Weiss et al. 1990; Herr et al. 2000a, b; Wills et al. 2008), a compact fold in this region is also supported by a major stop of 


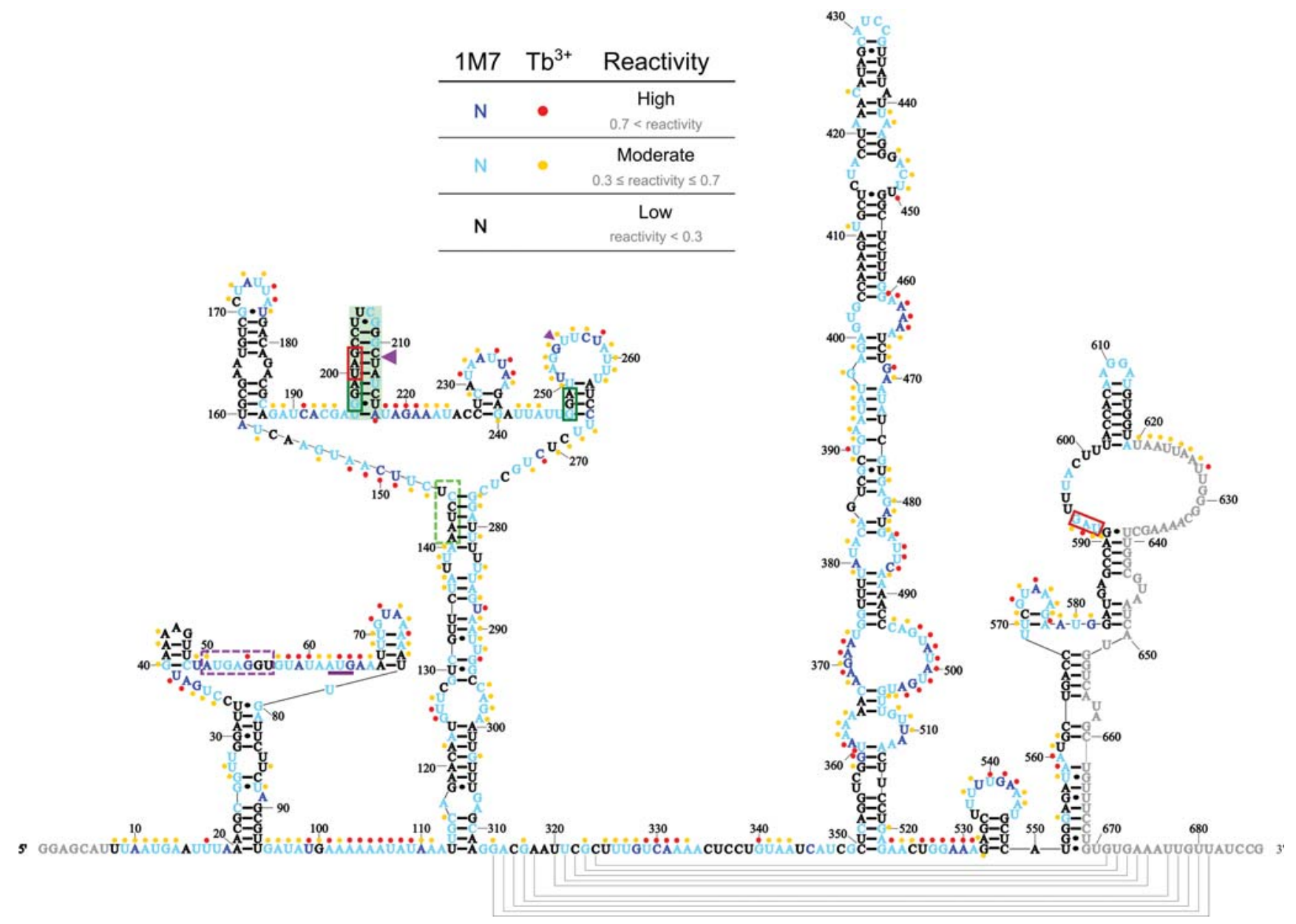

FIGURE 5. Secondary structure model of gene 60 mRNA generated from $1 \mathrm{M} 7$ data. The mRNA is rendered from $5^{\prime}$ to $3^{\prime}$ from left to right. Nucleotides are color-coded based on their reactivity range: low reactivity (black), moderate reactivity (light blue), high reactivity (dark blue). Colored circles indicate nucleotides that are moderately (orange) or highly (red) reactive with $\mathrm{Tb}^{3+}$. The gene 60 start codon is underlined in purple, the take-off and landing codons are boxed in green, and stop codons are boxed in red. The hairpin at the $5^{\prime}$ edge of the coding gap is shaded in green. Large and small purple triangles represent major and minor AMV reverse transcriptase stops, respectively, as determined by Huang et al. (1988). The SD of gene 60 mRNA and protected loop nucleotides (for details, see text) are enclosed in dashed purple and light green boxes, respectively.

AMV reverse transcriptase between nucleotides 211 and 212 (Figs. 4, 5, large purple triangle; Huang et al. 1988). Taken together, these data clearly support the presence of a hairpin at the $5^{\prime}$ edge of the coding gap.

In contrast, the rest of the coding gap (nucleotides 217249) reacted strongly with both reagents, producing an average reactivity of $0.54 \pm 0.10$ for $\mathrm{Tb}^{3+}$ and $0.50 \pm 0.14$ for $1 \mathrm{M} 7$. These data were unexpected given the potential for significant intramolecular base-pairing among these nucleotides and suggested that there is little (consistent) structure in the $3^{\prime}$ portion of the coding gap. An overlay of the $\mathrm{Tb}^{3+}$ reactivity from full-length gene $60 \mathrm{mRNA}$ onto previously proposed models in Figure 8, C-F, reveals that only a short stem-loop between the $5^{\prime}$ hairpin and the $3^{\prime}$ end of the coding gap is compatible with our experimental data (Fig. 8F). Lack of other well-defined structural motifs in this region may explain why mutational analyses in this region could not clearly sup- port or refute any predicted structural features important for bypassing (Weiss et al. 1990).

\section{Translational bypassing does not require base-pairing between the SD sequence and the coding gap}

While both experimentally derived secondary structure models of gene 60 mRNA contain the predicted hairpin at the $5^{\prime}$ edge of the coding gap, each renders its $3^{\prime}$ portion differently. The 1M7 model contains only the short stem-loop that fits our data from both reagents well (Fig. 8A,F). The $\mathrm{Tb}^{3+}$ models of both full-length and truncated gene 60 mRNA, however, render the coding gap in a base-pairing interaction with the strongly protected SD sequence of gene 60 mRNA (Figs. 4, 7 ). The complementarity of these regions was first noted in the original discovery of translational bypassing (Huang et al. 1988) but did not appear to be functionally critical 
TABLE 2. Fit of reactivity data to secondary structure models

\begin{tabular}{|c|c|c|c|c|}
\hline & \multicolumn{2}{|c|}{$\mathrm{Tb}^{3+}$ model } & \multicolumn{2}{|c|}{$1 \mathrm{M} 7$ model } \\
\hline & $\mathrm{Tb}^{3+}$ data & $1 \mathrm{M} 7$ data & $\mathrm{Tb}^{3+}$ data & 1M7 data \\
\hline $\begin{array}{l}\text { Mid-range }{ }^{\mathrm{a}} \text { nucleotides modeled correctly as } \\
\text { in single-stranded or base-paired category }\end{array}$ & $86 \%$ & $91 \%$ & $81 \%$ & $89 \%$ \\
\hline Mid-range $^{a}$ nucleotides unassignable & $57 \%$ & $46 \%$ & $52 \%$ & $44 \%$ \\
\hline Free energy of folded RNA & \multicolumn{2}{|c|}{$-142.6 \mathrm{kcal} / \mathrm{mol}$} & \multicolumn{2}{|c|}{$-108.6 \mathrm{kcal} / \mathrm{mol}$} \\
\hline
\end{tabular}

Assumptions are as follows: Nucleotides with reactivity greater than or equal to 0.7 should be single-stranded; nucleotides, less than or equal to 0.3 should be base-paired.

${ }^{\mathrm{a}}$ Mid-range nucleotides have reactivity between 0.3 and 0.7 .

(Huang et al. 1988; Weiss et al. 1990; Maldonado and Herr 1998; Herr et al. 2000b, 2001; Wills et al. 2008). To further test this notion, we prepared a gene 60 construct with a mutated SD sequence (CAT SD) that is no longer able to form extensive base-pairing interactions with the coding gap (Fig. 9A). Structure probing of this variant with either $\mathrm{Tb}^{3+}$ (Fig. 9B) or 1M7 (Fig. 9C) indeed showed an increase in the relative accessibility of part of the SD-complementary sequence in the coding gap, as expected, but the mutant yielded wild-type levels of translational bypassing (Fig. 9D). These observations suggest that SD:coding gap interaction, while present in a significant subset of molecules in solution, plays no functional role in translational bypassing. Accordingly, probing data of our bypassing-competent CAT SD gene 60 mRNA are consistent with a $5^{\prime}$ hairpin and short $3^{\prime}$ stem-loop in the coding gap (Fig. 9E), identical to the structure supported by wild-type SD gene 60 mRNA. These results are consistent with the notions that the SD sequence needs to be single-stranded for ribosomes to bind and initiate translation.

\section{Base-pairing between a protected loop complementary to the take-off and landing sites is not required for bypassing}

Intriguingly, nucleotides 141-146 reside in a large loop in the $\mathrm{Tb}^{3+}$ models (Figs. 4,7 ), yet are highly protected from both reagents. As nucleotides in large loops are usually very flexible and highly reactive, we searched for potential Watson-Crick binding partners of the protected nucleotides. Strikingly, the protected nucleotides are complementary to both the takeoff and landing codons. We therefore asked whether these nucleotides may in some way be involved in translational bypassing. They reside in the coding region for the critical nascent peptide sequence involved in bypassing (Weiss et al. 1990; Lovett 1994; Larsen et al. 1995; Choi and Brimacombe 1998; Choi et al. 1998; Herr et al. 2000a,b, 2001; Wills et al. 2008). Previous mutations of this region to synonymous codons demonstrated that the protein sequence rather than the nucleotide sequence is critical for bypassing (Weiss et al. 1990). We independently verified this result by mutating the protected nucleotides to synonymous codons, disrupting their ability to interact with the take-off and landing codons; we observed no effect on translational bypassing (data not shown).

There are several other potential base-pairing partners for loop nucleotides 141-147 throughout the length of gene 60 mRNA. In the $1 \mathrm{M} 7$ model, these protected residues are paired with nucleotides 277-282. They are also complementary to nucleotides 29-33 within the $5^{\prime}$ UTR, 52-55 in the SD of gene 60 mRNA, 312-315, 398-401, 444-447, 530-534, $552-555$, and 609-613, the loop of the likely natural transcription terminator for gene 60 . As protection of nucleotides 141-147 is observed in a truncated version of gene 60 mRNA as well (Fig. 7), the most likely base-pairing partners are nucleotides 29-33 and 52-55. Yet these interactions, if present in solution, are not required for translational bypassing.

Alternatively, the protected loop nucleotides may indicate a local structural motif. Similar C- and U-rich loop regions in other RNAs have been found to have low reactivity toward SHAPE reagents (Legiewicz et al. 2010), in part because of the slightly lower reactivity of $\mathrm{C}$ and $\mathrm{U}$ nucleotides compared with A and G (Wilkinson et al. 2009). Our $\mathrm{Tb}^{3+}$ data, however, exhibit the same protection of these nucleotides as 1M7. Since runs of Cs can form helices that are significantly more stable than those of other homopolymers (Seol et al. 2007), it is conceivable that there exists a local stabilizing structure in this region that protects it from structure probing reagents.

\section{The coding gap in gene $60 \mathrm{mRNA}$ is structurally autonomous}

Based on the results presented thus far, it appears that the coding gap (1) is mostly unstructured except for the $5^{\prime}$ hairpin and a short downstream stem-loop, (2) does not interact with sequence $3^{\prime}$ of the landing codon, and (3) does not need to interact with complementary regions in the $5^{\prime}$ region of gene $60 \mathrm{mRNA}$, specifically the SD or protected loop nucleotides 141-147, for bypassing to occur. To further test this apparent structural autonomy of the coding gap, we probed the structure of the gene 60 mRNA that lacks the entire 50-nt insertion ("60 $\Delta$ gap"). Figure 10 compares both the $1 \mathrm{M} 7$ and $\mathrm{Tb}^{3+}$ reactivities at each nucleotide position along the gene 
A

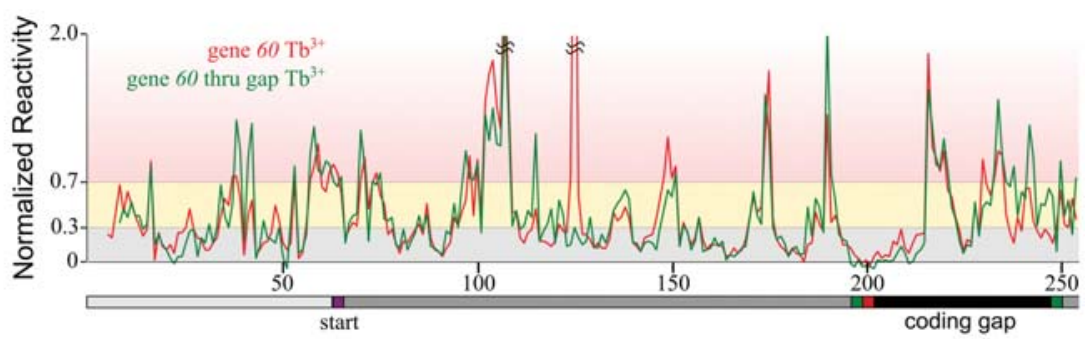

B

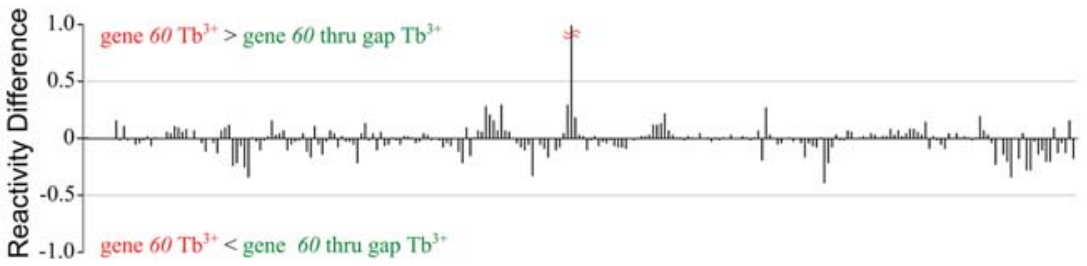

C

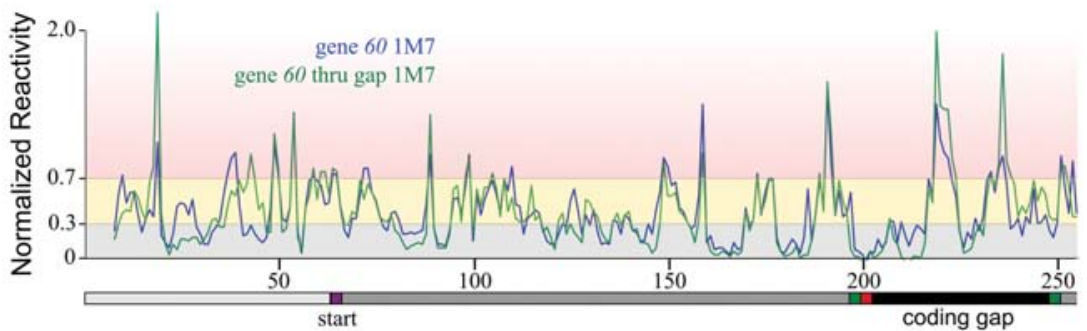

D

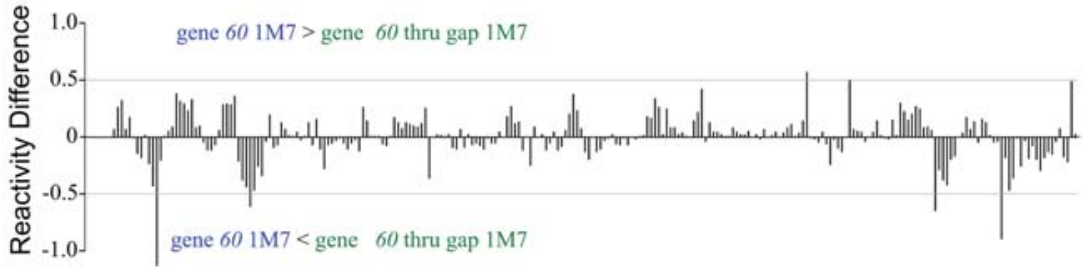

FIGURE 6. Comparison of reactivity between full-length gene 60 and gene 60 thru gap mRNA. (A) Normalized average reactivity from $\mathrm{Tb}^{3+}$ probing for full-length gene 60 (red) and gene 60 thru gap (green) mRNA. The $x$-axis indicates the nucleotide position in gene $60 \mathrm{mRNA}$, with gene 60 translation start site and coding gap region indicated. Shading is as described in Figure 3. (B) Difference between full-length gene 60 and gene 60 thru gap $\mathrm{Tb}^{3+}$ reactivity at each nucleotide position ( $x$-axis scale is identical to that in $A$ ). $(C)$ Normalized average reactivity from 1M7 probing for full-length gene 60 (blue) and gene 60 thru gap (green) mRNA. (D) Difference between full-length gene 60 and gene 60 thru gap 1M7 reactivity at each nucleotide position $(x-$ axis scale is identical to that in $C$ ).

60 and "60 $\Delta$ gap" mRNAs. Difference plots reveal that the patterns and intensities of reactivity along the two mRNAs are almost identical (Fig. 10B,D). Minor perturbations in reactivity observed on either side of the coding gap are likely caused by changes in local structural environment in the presence or absence of the coding gap. Accordingly, predicting the secondary structure of gene "60 $\Delta$ gap" mRNA using RNAstructure and either the $\mathrm{Tb}^{3+}$ or $1 \mathrm{M} 7$ reactivity data as pseudo-free energy constraints generated structures almost identical to those of the wild-type gene 60 mRNA (data not shown). We conclude that the coding gap is an independent sequence element that only weakly interacts with any other part of gene $60 \mathrm{mRNA}$, as its removal has no significant impact on the remainder of the structure.

\section{DISCUSSION}

Under in vitro conditions where $\mathrm{T} 4 \mathrm{bac}-$ teriophage gene 60 mRNA shows a typical translational bypassing efficiency of $50 \%$, structure probing using either $\mathrm{Tb}^{3+}$ or SHAPE reagents, which both detect the accessibility of 2'-OH groups, yields distinct secondary structure models. The $\mathrm{Tb}^{3+}$-derived model fits better to both data sets and is thermodynamically more stable, consistent with the notion that $\mathrm{Tb}^{3+}$ ions stabilize a major solution structure of the mRNA. Key differences between the models occur at the SD sequence of gene $60 \mathrm{mRNA}$, which is single-stranded in the 1M7 model but forms extensive base-pairing interactions with the coding gap in the $\mathrm{Tb}^{3+}$ model. Conversely, six unreactive nucleotides with potential complementarity to the take-off and landing sites are involved in unrelated base-pairing interactions in the 1M7 model yet are rendered single-stranded in a large loop in the $\mathrm{Tb}^{3+}$ model. We found both of these potential base-pairing interactions with the coding gap to be unnecessary for translational bypassing. Furthermore, the sequence downstream from the coding gap also does not interact with the coding gap or the $5^{\prime}$ region of gene $60 \mathrm{mRNA}$, as probing of a minimal, more homogenously folded mRNA ("60 thru gap") generates similar structures to the $5^{\prime}$ portion of fulllength models. Given the sum of this structural and functional information, we conclude that the functional coding gap only requires a very stable $5^{\prime}$ hairpin and a short downstream stem-loop (Fig. 8F). This model of the coding gap is consistent with only one of several models previously proposed by Le et al. (1993) based on a purely computational prediction of secondary structures that are energetically within $20 \%$ of the lowestenergy conformation (Fig. 8F). The coding gap thus does not functionally require any base-pairing with an upstream or downstream sequence, making it structurally autonomous.

There are several possible origins for the systematic reactivity differences we observe between the $\mathrm{Tb}^{3+}$ and SHAPE probing reagents, even after careful normalization and crossvalidation of the data sets. First, since cationic metal ions often critically stabilize secondary and tertiary structure elements in negatively charged RNA, the addition of trivalent $\mathrm{Tb}^{3+}$ ions may capture transiently sampled structures in gene 


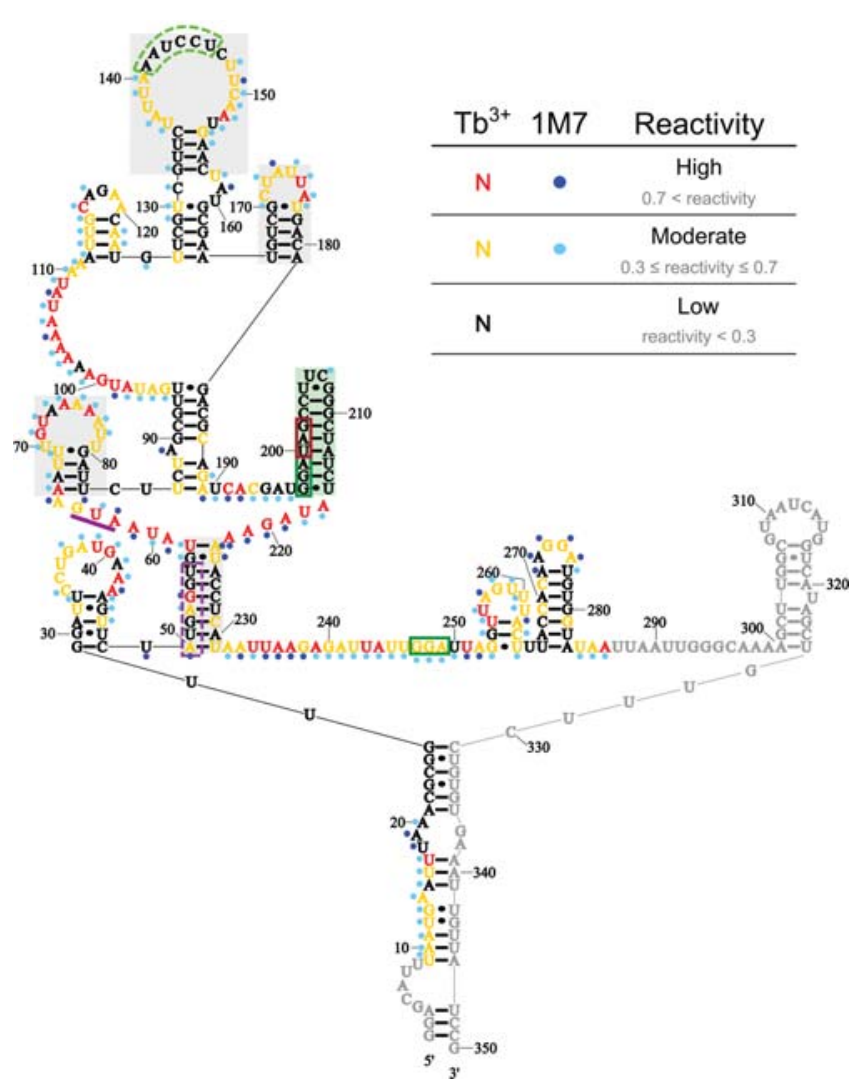

FIGURE 7. Secondary structure model of gene 60 thru gap mRNA consistent with $\mathrm{Tb}^{3+}$ data with $1 \mathrm{M} 7$ data overlaid. Colors and symbols are as described in Figure 4. The $5^{\prime}$ hairpin is shaded in green, while other structural features in common between full-length and gene 60 thru gap mRNA are shaded gray.

60 mRNA, leading to a lower reactivity of some nucleotides with $\mathrm{Tb}^{3+}$ than with $1 \mathrm{M} 7$. Conversely, SHAPE reagents were recently found to preferably react with nucleotides on whose nucleo bases they can stack (Steen et al. 2012), suggesting that they may have an effect opposite that of $\mathrm{Tb}^{3+}$ by destabilizing intramolecular (stacking) interactions in the probed RNA. Second, several nucleotides that are well-ordered in the small ribosomal crystal structure have been shown to be hyper-reactive to SHAPE reagents. This unexpectedly high reactivity was attributed to local effects such as potential general base catalysis by RNA functional groups and specific orientations of the flanking $3^{\prime}$ phosphate group (McGinnis et al. 2012), which may occur in gene $60 \mathrm{mRNA}$ as well. Third, $\mathrm{Tb}^{3+}$ ions bind preferentially to and can displace metals from cation binding sites (Hargittai and Musier-Forsyth 2000; Walter et al.2000). Nucleotides proximal to specific metal ion binding sites may thus be expected to be more reactive to $\mathrm{Tb}^{3+}$, while potentially being protected from SHAPE reagents. Fourth, potential differences in reactivity may arise due to the difference in timescale at which the two reagents modify RNA. At $37^{\circ} \mathrm{C}, \mathrm{Tb}^{3+}$ reactions were incubated for $30 \mathrm{~min}$, whereas $1 \mathrm{M} 7$ reactions are complete after only $4 \mathrm{~min}$. Because $\mathrm{Tb}^{3+}$ reacts more slowly than $1 \mathrm{M} 7$, the $\mathrm{Tb}^{3+}$ data may be more likely to average over slowly interchanging conformations of the RNA, while 1M7 data are expected to reflect a shorter "snapshot" of an RNA structure (Gherghe et al.2008). This difference may be particularly significant in light of the fact that our EMSA analysis revealed that gene $60 \mathrm{mRNA}$ adopts an ensemble of conformations (Fig. 2C), which may interchange. It should further be noted that a recent error assessment of SHAPE-derived structural models found a significant frequency of each $\sim 20 \%$ false-negative and falsepositive discovery, independent of variations in data processing, normalization, and modeling parameters (Kladwang et al. 2011). This error rate is consistent with the extent of discrepancies between our $\mathrm{Tb}^{3+}$ and $1 \mathrm{M} 7$ models and suggests that the inclusion of a second reagent class, such as $\mathrm{Tb}^{3+}$ ions, may generally be advisable to obtain more reliable results from secondary structure probing experiments.

Highly structured segments, such as pseudoknots and stable hairpins, have been shown to modulate the movement of the ribosome along an mRNA inducing shifts in reading frame (Farabaugh 1996; Herr et al. 2000a; Kontos et al. 2001; Giedroc and Cornish 2009; Mazauric et al. 2009; Chou and Chang 2010; Chung et al. 2010), presumably due to the difficulty that the ribosome has unwinding complex, stable structures (Firth and Brierley 2012). In these cases, multiple protein products are encoded in overlapping reading frames, and the efficiency of the frameshifting event determines the relative ratio at which each protein is expressed (Farabaugh 1996; Chou and Chang 2010). In these ways, mRNA provides additional layers of regulation for gene expression beyond those at the DNA and protein levels (Herr et al. 2000a; Kontos et al. 2001). When probing the secondary structure of an mRNA, highly structured regions in an ORF or between ORFs often indicate critical points for regulation during translation (Watts et al. 2009). In contrast, coding regions of mRNAs are relatively unstructured compared with regulatory elements, presumably to prevent significant delays during translation (Wilkinson et al. 2008; Watts et al. 2009). An example is found in the HIV-1 genome, where the 335-nt-long 5' UTR contains several well-known, highly structured regulatory elements required for viral replication and packaging, whereas the next 600-nt code for viral proteins. In accordance with these functional differences, the median SHAPE reactivity in the 5 ' UTR was 0.13 , whereas coding regions had a median reactivity of 0.40 (Wilkinson et al. 2008). Thus, probing data accurately reflect the facts that regulatory regions of mRNA are structured and coding regions tend to lack such structures.

Our final model of the bypassing-competent secondary structure of the coding gap is inconsistent with the previous expectation to find significant secondary structure to choreograph translational bypassing. (Huang et al. 1988; BurkeAguero and Hearst 1990; Le et al. 1993; Wills et al. 2008). In contrast, we have shown that aside from the stable $5^{\prime}$ hairpin, the coding gap contains little additional structure with itself or the rest of gene 60 mRNA in solution. This autonomy is consistent with the recent finding that the coding gap is a foreign 
A
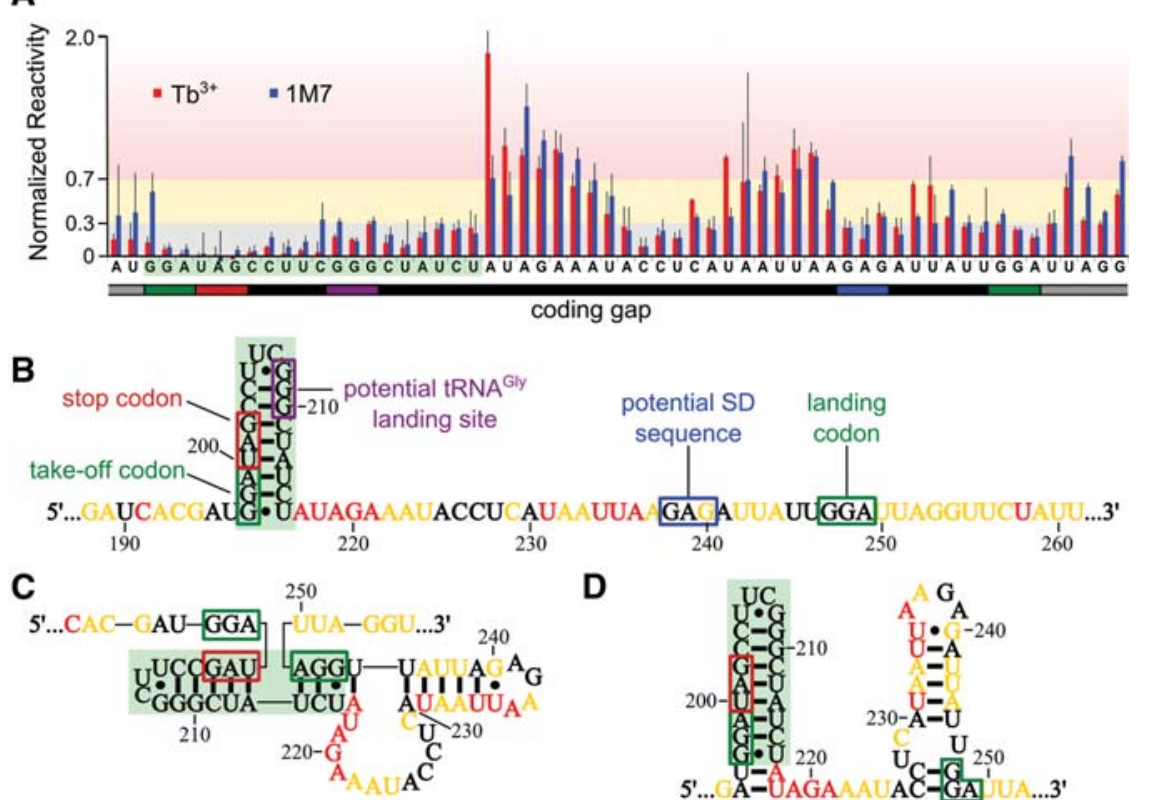

250

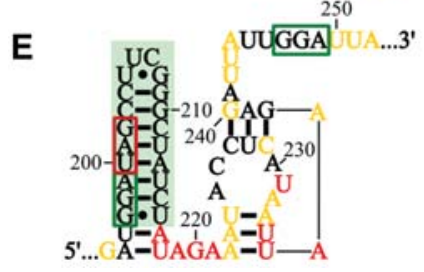

FIGURE 8. Compatibility between experimental probing data and previously proposed models. (A) Normalized reactivity for coding gap nucleotides from full-length gene $60 \mathrm{mRNA}$. $\mathrm{Tb}^{3+}$ data are red, and 1M7 data are blue. Shading is as described in Figure 3. (B) mRNA sequence of the gene 60 mRNA coding gap. Important coding gap features are labeled. Nucleotides are color-coded based on their $\mathrm{Tb}^{3+}$ reactivity range in full-length gene $60 \mathrm{mRNA}$, and the $5^{\prime}$ hairpin is shaded in green. Secondary structure models of the coding gap proposed by Huang et al. (1988) and Burke-Aguero et al. (1990) (C) and Le et al. (1993) (D-F; nucleotide colors as in B).

2001). After decoding the Gly codon, the in-frame stop codon would lie directly in the A-site, ready to trigger termination by RF2. At natural cellular levels of RF2, however, termination does not compete with bypassing since all ribosomes take-off even though only $\sim 50 \%$ are able to complete the bypassing event and continue translating (Herr et al. 2000b). This observation indicates either that bypassing must initiate quickly after decoding of the takeoff Gly codon or that some other feature prevents RF2 from sampling the A-site stop codon. In the crystal structure of the $70 \mathrm{~S}$ ribosome bound to a short (36-nt) mRNA, the mRNA forms a hairpin with a 4-bp stem and a tetraloop in the A-site of the ribosome, overlapping the natural codon-anticodon interaction region (Yusupova et al. 2001). With the take-off Gly codon in the Psite, the top portion of the $5^{\prime}$ hairpin in the coding gap could similarly form a short hairpin in the A-site, preventing recognition of the stop codon by RF2. This model is supported by the fact that the UUCG loop found in the $5^{\prime}$ hairpin has a propensity to form a tight structure, stabilized by an extensive hydrogen bonding network (Ennifar et al. 2000). For Huang et al. (1988), this hairpin generated a major stop between nucleotides 211 and 212 during primer extension with AMV reverse

DNA element (Bonocora et al. 2011) that can be inserted into genes whose sequences do not necessarily contain regions of complementary. Although mostly unstructured, the entire coding gap is important for bypassing as deletions of its $3^{\prime}$ portion reduce bypassing efficiency (Weiss et al. 1990; Herr et al. 2000a), and the entire and exact sequence of the coding gap is always transmitted during MobA homing (Repoila et al. 1994; Bonocora et al. 2011). The unstructured portion could function as a single-stranded spacer and ribosome landing platform, fold into a distinct structure cotranslationally, and/or recruit cellular cofactors required for bypassing. In the minimum, it provides a potential SD-like sequence for anchoring the ribosome near the landing codon (Fig. 1B), analogous to the recent observation that SD-like sequences in coding regions often cause transient ribosome arrest ( $\mathrm{Li}$ et al. 2012).

The site of take-off during translational bypassing occurs within the critical hairpin structure of the coding gap. To decode the take-off Gly codon, the ribosome presumably must first unwind this stable hairpin as it only allows singlestranded RNA to pass into the mRNA entry tunnel (Culver transcriptase (Figs. 4, 5); it also caused persistent peak compression in our electropherograms of cDNAs ending in nucleotides complementary to 202-205 (data not shown). In the crystal structure of the 70S ribosome, slippage may have occurred due to the short length of the mRNA (Yusupova et al. 2001), whereas in the case of gene 60 mRNA, stalling of the ribosome may allow the top of the $5^{\prime}$ hairpin to reform and reject RF2. In addition, the $\mathrm{N}$ terminus of the nascent peptide chain has been found to cross-link with the peptidyltransferase center (Choi and Brimacombe 1998) as well as to ribosomal proteins S1, S2, S3, and S4 (Choi et al. 1998). S3, S4, and S5 form a tunnel through which single-stranded mRNA is brought into the peptidyl transferase center (Culver 2001). Thus, it is possible that the nascent peptide sequence alters the geometry of the decoding center and/or interferes with the natural unwinding ability of the mRNA entrance tunnel, allowing extra mRNA to enter and fold in the A-site.

Alternative to just the top of the $5^{\prime}$ hairpin folding in the A-site, Wills et al. (2008) identified protein products of 


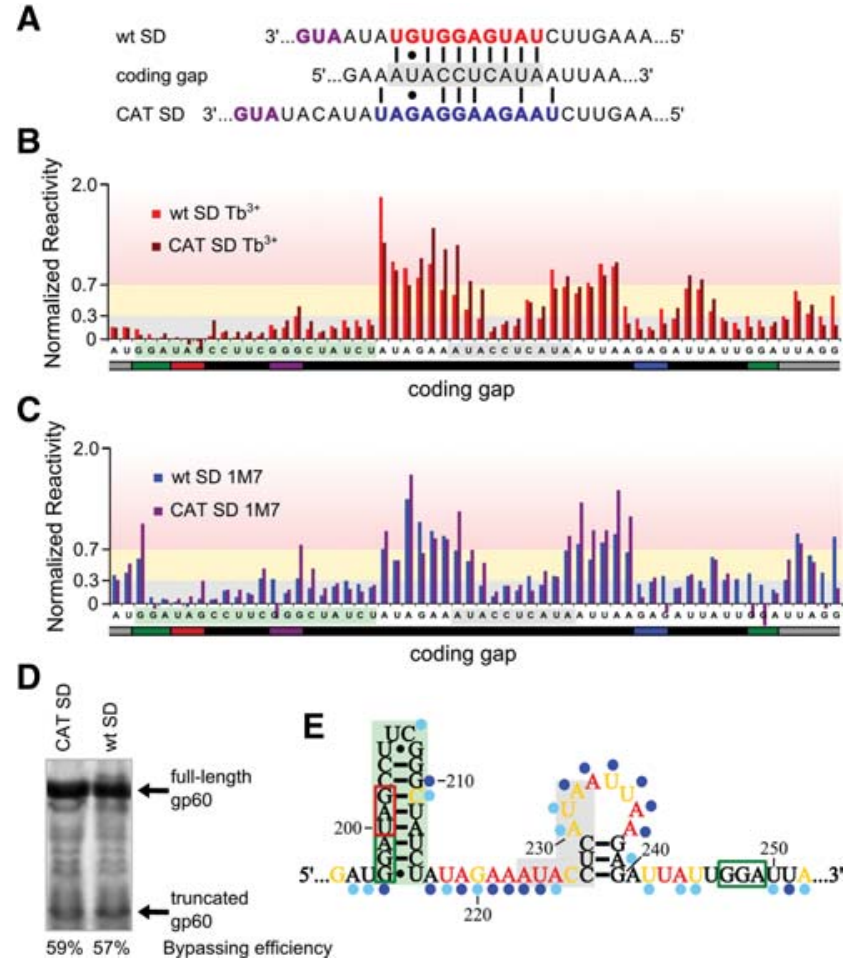

FIGURE 9. The coding gap reactivity does not change significantly in the absence of the wild-type gene 60 SD (wt SD). (A) Mutation of the wild-type gene $60 \mathrm{SD}$ (red) to that of the chloramphenicol acetyl transferase (CAT) gene (blue). Start codons are purple, and the portion of the coding gap complementary to the wt $\mathrm{SD}$ is shaded in gray. (B) Comparison of reactivity of wt SD gene 60 (red) and CAT SD gene 60 (brown) coding gap nucleotides with $\mathrm{Tb}^{3+}$. The $5^{\prime}$ hairpin nucleotides are shaded in green, and the portion of the coding gap complementary to the wt SD is shaded in gray. $(C)$ Comparison of reactivity of wt SD gene 60 (blue) and CAT SD gene 60 (purple) coding gap nucleotides with $1 \mathrm{M} 7 .(D)$ In vitro translation products of gene 60 with the wt or CAT SD. Bypassing efficiency for each template is indicated. (E) Secondary structure model of the coding gap region generated from probing data for CAT SD gene 60 mRNA (both $\mathrm{Tb}^{3+}$ and 1M7 probing generated models contain this coding gap structure). Shading is as described in $B$, and colors and symbols are as described in Figure 4.

bypassing to codons upstream of the take-off site, which supports the notion that mRNA can be pulled into the A-site from the $5^{\prime}$ direction. The investigators hypothesized that, once released from the peptidyl-tRNA, the entire coding gap may be pulled from both the $3^{\prime}$ and $5^{\prime}$ directions to fold in the A-site. Furthermore, toeprinting of small ribosomal subunits bound in the presence of charged tRNAs to an mRNA containing the coding gap sequence just downstream from a strong SD element is significantly shorter than expected for a linear mRNA (Ringquist et al. 1993). These results are consistent with the idea that the entire coding gap may be able to fold into a compact structure only in the presence of the ribosome. Future structural studies of gene $60 \mathrm{mRNA}$ in the presence of the ribosome may be able to resolve this question; free in solution, however, our data show that such a more compact secondary structure is at most a minor conformation.

\section{MATERIALS AND METHODS}

\section{Preparation of gene $60 \mathrm{mRNA}$ mutants}

A clone of gene 60 in pUC19 was generated by PCR directly from the T4 phage genome. This construct contained the gene $60 \mathrm{ORF}$, flanked by $61 \mathrm{nt}$ of its natural $5^{\prime}$ UTR and $41 \mathrm{nt}$ of its natural $3^{\prime}$ UTR, under transcriptional control of a T7 promoter. Site-directed mutagenesis to prepare all mutants was performed as follows. Briefly, primers (Invitrogen) were phosphorylated with T4 polynucleotide kinase (New England Biolabs) and used to amplify portions of gene 60 by PCR in the presence of Taq DNA ligase (New England Biolabs). Following digestion of template plasmids with DpnI (New England Biolabs), mutant plasmids were transformed into JM109 cells (Promega), and resulting clones were sequenced to confirm mutations. Primers used for site-directed mutagenesis are listed in Table 1.

Gene $60 \mathrm{mRNA}$ was transcribed in vitro for $1 \mathrm{~h}$ at $37^{\circ} \mathrm{C}$ with $50 \mathrm{nM}$ plasmid linearized with BsrBI (New England Biolabs), $40 \mathrm{mM}$ Tris$\mathrm{HCl}$ (pH 8.0), $25 \mathrm{mM} \mathrm{MgCl}_{2}, 100 \mathrm{mM} \mathrm{NaCl}, 0.01 \%$ Triton-X, $5 \mathrm{mM}$ DTT, $1 \mathrm{mM}$ spermidine, $12 \mathrm{mM}$ each NTP, 0.01 units/ $\mu \mathrm{L}$ pyrophosphatase (MP Biomedicals), and $0.065 \mathrm{mg} / \mathrm{ml}$ T7 RNA polymerase (homemade). RNA was purified by denaturing PAGE and stored at $-20^{\circ} \mathrm{C}$ in $\mathrm{TE}(10 \mathrm{mM}$ Tris- $\mathrm{HCl}$ at $\mathrm{pH} 7.0,1 \mathrm{mM}$ EDTA $)$.

\section{In vitro translation assay conditions}

S30 extracts were prepared essentially according to the method previously described (Pratt 1984) from BL21 Star(DE3) cells (Invitrogen) after induction of T7 RNA polymerase for $1.5 \mathrm{~h}$ at $37^{\circ}$ C. In vitro translation reactions were carried out as according to the method described previously (Kigawa et al. 2004). Briefly, 10 $\mu \mathrm{L}$ reactions contained $4 \mu \mathrm{L}$ of $2.5 \times \mathrm{S} 30$ premix (S30 buffer [55 $\mathrm{mM}$ Hepes- $\mathrm{KOH}$, at $\mathrm{pH} 7.5,210 \mathrm{mM}$ potassium glutamate, 27.5 $\mathrm{mM}$ ammonium acetate, $10.7 \mathrm{mM}$ magnesium acetate, $1.7 \mathrm{mM}$ DTT], $1.2 \mathrm{mM}$ ATP, $0.8 \mathrm{mM}$ CTP, $0.8 \mathrm{mM}$ GTP, $0.8 \mathrm{mM}$ UTP, $640 \mu \mathrm{M}$ cAMP, $68 \mu \mathrm{M}$ folinic acid, $175 \mu \mathrm{g} / \mathrm{mL}$ total tRNA from E. coli MRE600 [Roche], $80 \mathrm{mM}$ creatine phosphate, $75 \mathrm{U}$ creatine phosphokinase [Roche], 4\% [w/v] PEG 8000); $2 \mu \mathrm{L}$ S30 extract; 50 nM mRNA or DNA template; $0.1-1 \mu \mathrm{L}$ of $10 \mu \mathrm{Ci} / \mu \mathrm{L}{ }^{35} \mathrm{~S}$-Met, or ${ }^{35} \mathrm{~S}$-Cys $(\sim 1 \mu \mathrm{Ci}$ per reaction); and water (as necessary). Reactions were assembled on ice and incubated for $30 \mathrm{~min}$ at $37^{\circ} \mathrm{C}$. One microliter of $1 \mathrm{M} \mathrm{KOH}$ was added to quench the reaction and cleave any remaining peptide from their tRNAs. Protein products were precipitated with $50 \mu \mathrm{L}$ of cold acetone and pelleted by centrifugation at 20,000 rcf for $10 \mathrm{~min}$ at room temperature. Pellets were resuspended in $15 \mu \mathrm{L}$ of $1 \times$ loading buffer $(100 \mathrm{mM}$ Tris- $\mathrm{HCl}$ at $\mathrm{pH}$ 6.8, 24\% glycerol, 2\% [w/v] SDS, 200 mM DTT, 0.02\% Coomassie blue), and protein products were resolved on a $20 \%$ Tris-Tricine gel at $150 \mathrm{~V}$ for $\sim 4 \mathrm{~h}$ or until dye ran completely off the gel. Gels were soaked for $1 \mathrm{~h}$ in $5 \%(\mathrm{v} / \mathrm{v})$ glycerol, $40 \%(\mathrm{v} / \mathrm{v})$ methanol, and $10 \%$ $(\mathrm{v} / \mathrm{v})$ acetic acid and dried onto 3-mm Whatman paper (Biorad Model 583 Gel Dryer). A phosphor storage screen and Typhoon 9410 Variable Mode Imager (GE Healthcare Life Sciences) were used to quantify bands, and bypassing efficiency was calculated as the intensity of full-length gp60 divided by the sum of intensities from full-length and truncated gp60 bands. We note that fulllength gp60 contains twice as many Met residues as truncated gp60; therefore when labeling with ${ }^{35} \mathrm{~S}$-Met, the intensity of fulllength gp60 was divided by two before comparison to truncated gp60 intensity. 
A

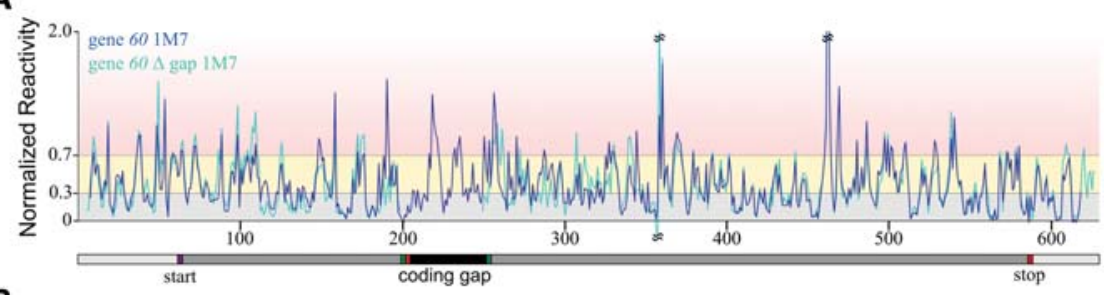

B

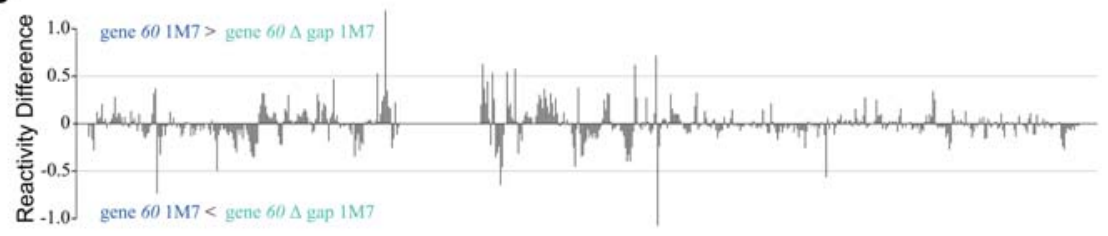

C

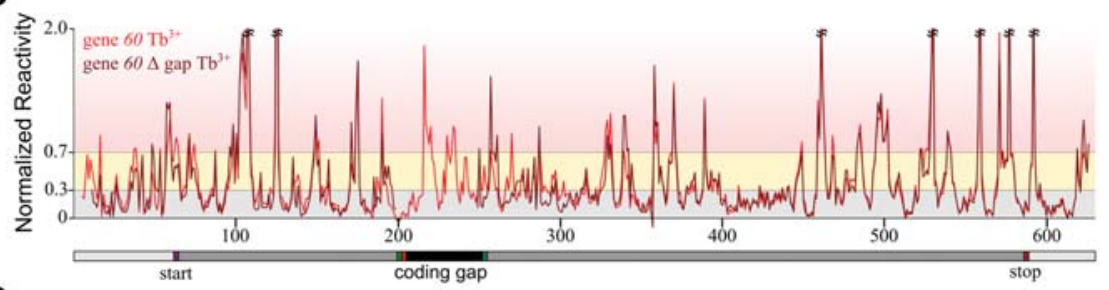

D

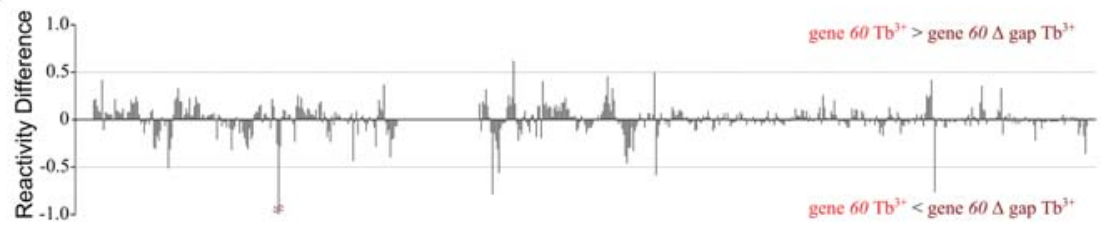

FIGURE 10. Comparison of reactivity between gene 60 and gene $60 \Delta$ gap mRNA. (A) Normalized average reactivity from $1 \mathrm{M} 7$ probing for gene 60 (dark blue) and gene $60 \Delta$ gap (light blue) mRNA. The $x$-axis indicates the nucleotide position in gene $60 \mathrm{mRNA}$, with the gene 60 translation start site and coding gap region indicated. Shading is as described in Figure 3. (B) Difference between gene 60 and gene $60 \Delta$ gap mRNA 1 M7 reactivity at each nucleotide position ( $x$-axis scale is identical to that in $A$ ). $(C)$ Normalized average reactivity from $\mathrm{Tb}^{3+}$ probing for gene 60 (red) and gene $60 \Delta$ gap (brown) mRNA. (D) Difference between gene 60 and gene $60 \Delta$ gap $\mathrm{Tb}^{3+}$ reactivity at each nucleotide position ( $x$-axis scale is identical to that in $C$ ).

\section{Structure determination of gene $60 \mathrm{mRNA}$}

Gene 60 mRNA was probed essentially according to the method previously described (Harris and Walter 2003, 2005; Jeong et al. 2003; Harris et al. 2004; Sefcikova et al. 2007b; Watts et al. 2009). Briefly, a pool of gene $60 \mathrm{mRNA}$ was diluted to $0.2 \mathrm{pmol} / \mu \mathrm{L}$ in $\mathrm{TE}(\mathrm{pH} 7.0$ ), heat denatured for $1 \mathrm{~min}$ at $90^{\circ} \mathrm{C}$, and snap cooled on ice. The mRNA pool was refolded in $\mathrm{S} 30$ buffer for $15 \mathrm{~min}$ at $37^{\circ} \mathrm{C}$. Refolded mRNA was divided into individual tubes containing $1 \mathrm{pmol}(9 \mu \mathrm{L})$ each. Multiple negative control reactions and dideoxy sequencing reactions were performed in parallel as pools.

For $\mathrm{Tb}^{3+}$ probing, $1 \mu \mathrm{L}$ of a $10 \mathrm{mM}$ stock of $\mathrm{TbCl}_{3}$ in water was added to each reaction sample, and $1 \mu \mathrm{L}$ of water was added to negative controls. Reactions were incubated for $30 \mathrm{~min}$ at $37^{\circ} \mathrm{C}$ and quenched by adding $1 \mu \mathrm{L}$ of $50 \mathrm{mM}$ EDTA (Harris and Walter 2003, 2005). SHAPE probing was performed similarly, wherein $1 \mu \mathrm{L}$ of a $20 \mathrm{mM}$ stock of SHAPE reagent in DMSO was added to each reaction sample, and $1 \mu \mathrm{L}$ of neat DMSO was added to negative controls. SHAPE reactions were incubated at $37^{\circ} \mathrm{C}$ for five reagent half-lives ( $4 \mathrm{~min}$ ), and then $1 \mu \mathrm{L}$ of 50 mM EDTA was added (Watts et al. 2009). Each sample was precipitated with $1 \mu \mathrm{L}$ of $20 \mu \mathrm{g} / \mu \mathrm{L}$ glycogen per pmol RNA, $1 / 10$ volume of $3 \mathrm{M} \mathrm{NH}_{4} \mathrm{OAc}$ and 3 volumes of ethanol. The RNA was pelleted by centrifugation at $20,000 \mathrm{rcf}$ for $30 \mathrm{~min}$ at $4^{\circ} \mathrm{C}$, washed with $70 \%(\mathrm{v} / \mathrm{v})$ ethanol, and dried under vacuum.

$5^{\prime}$ Fluorophore-labeled probes were ordered from Invitrogen (with 6-FAM, HEX, and ROX) or Applied Biosystems (NED). Two primers were necessary to obtain data for the entire length of gene 60 mRNA (686 nt). The first primer was complementary to the very $3^{\prime}$ end of gene 60 mRNA (5'-CGGATAACAATTTCACACAGGAAAC AGC- $\left.3^{\prime}\right)$, whereas the second bound to gene 60 mRNA just after the coding gap from nucleotides 338-359 (5'-CCGACCTGAGC GATGATTACAG-3'). Chemically probed RNAs were resuspended with $10 \mu \mathrm{L}$ of $0.5 \times \mathrm{TE}(\mathrm{pH} 8.0)$ and annealed with $3 \mu \mathrm{L}$ of $400 \mathrm{nM}$ fluorophore-labeled primer for $5 \mathrm{~min}$ at $65^{\circ} \mathrm{C}$, followed by $2 \mathrm{~min}$ at $45^{\circ} \mathrm{C}$. Seven microliters of reverse transcription master mix $(4 \mu \mathrm{L}$ Invitrogen Superscript III first strand buffer, $1 \mu \mathrm{L} 100 \mathrm{mM}$ DTT, $1 \mu \mathrm{L} 10 \mathrm{mM}$ dNTPs, and $1 \mu \mathrm{L}$ Invitrogen SuperScript III Reverse Transcriptase) was preheated for $1 \mathrm{~min}$ to $45^{\circ} \mathrm{C}$ and added to each reaction tube. Once mixed, reactions were transferred for $5 \mathrm{~min}$ to $52^{\circ} \mathrm{C}$, followed by $5 \mathrm{~min}$ at $65^{\circ} \mathrm{C}$, and then placed on ice. Dideoxy sequencing reactions were performed on the gene 60 mRNA according to the method previously described (Watts et al. 2009) except that each reverse transcription reaction also contained 500 nM of either ddATP or ddTTP. Twenty microliters of the probing reaction, the negative control, and each of the dideoxy sequencing reactions were combined and precipitated with $1 / 10$ volume of $\mathrm{NH}_{4} \mathrm{OAc}$ and 3 volumes of ethanol. cDNA was pelleted by centrifugation at 20,000 $\mathrm{rcf}$ for 30 $\min$ at $4^{\circ} \mathrm{C}$, washed with $70 \%(\mathrm{v} / \mathrm{v})$ ethanol, and dried under vacuum. Pellets were resuspended in $12 \mu \mathrm{L}$ of Hi-Di Formamide (Applied Biosystems) and loaded onto a 96-well optical reaction plate (Applied Biosystems). Plates were submitted to the University of Michigan Sequencing Core for fragment analysis by CE on an Applied Biosystems 3730XL capillary sequencer.

Raw electropherograms were analyzed with the ShapeFinder software (Vasa et al. 2008) and normalized in Excel according to the method previously described (Mortimer and Weeks 2008). The data presented are the average of three independent structure probing experiments, and the relative error at each nucleotide position is generally less than 0.1 normalized units (Vasa et al. 2008; Watts et al. 2009). Structural models were generated using the Max Expect and ProbKnot functions in RNAstructure (Reuter and Mathews 2010) using the normalized reactivity of each nucleotide as pseudo-free energy constraints. Both algorithms produced similar structures, 
indicating that no pseudoknots were supported by our experimental data. The resulting secondary structures were rendered in Inkscape (http://inkscape.org/). A rough estimate of the congruency between each data set and each model was derived by assuming nucleotides with reactivity $>0.7$ should be single-stranded and nucleotides with reactivity $<0.3$ should be structured (we note that these calculations do not take into account causes other than Watson-Crick base pairs for low reactivity). Two separate calculations were performed, one assuming nucleotides with reactivity between 0.3 and 0.7 were correctly rendered in our model regardless of their environment (singleor double-stranded). In the second calculation, these mid-range nucleotides were deemed not assignable. The results of these calculations are presented in Table 2.

\section{Electrophoretic mobility shift assay (EMSA)}

One microgram of each mRNA was refolded in S30 buffer as described above and resolved on a 6\% THEMA native gel $(34 \mathrm{mM}$ Tris, $66 \mathrm{mM}$ HEPES, $100 \mu \mathrm{M}$ EDTA, and $10 \mathrm{mM}$ magnesium acetate) (Woodson 2001) for $7 \mathrm{~h}$ at $4^{\circ} \mathrm{C}$ and $15 \mathrm{~W}$. Gels were stained in $1 \times$ SYBR Gold (Invitrogen) for $20 \mathrm{~min}$, and bands were visualized by UV illumination.

\section{ACKNOWLEDGMENTS}

We thank Rachel Green (Johns Hopkins University) and Hani Zaher (Washington University in St. Louis) for protocols, reagents, training, and helpful discussions pertaining to in vitro translation; John Hoerter (Genomics Institute of the Novartis Research Foundation) for generating the original pUC19 plasmid containing gene 60; Kevin Weeks (University of North Carolina at Chapel Hill) for help with setting up our SHAPE probing; and the group of Roger Sunahara (University of Michigan) for a mutagenesis protocol. We also thank Walter lab members Paul Lund and Matthew Marek for critical reading of this manuscript, and the latter for preparation of the SHAPE reagent 1M7. We acknowledge funding from NIH grant R01 GM062357.

Received November 10, 2012; accepted January 26, 2013.

\section{REFERENCES}

Bonocora RP, Zeng Q, Abel EV, Shub DA. 2011. A homing endonuclease and the 50-nt ribosomal bypass sequence of phage T4 constitute a mobile DNA cassette. Proc Natl Acad Sci 108: 16351-16356.

Bucklin DJ, Wills NM, Gesteland RF, Atkins JF. 2005. P-site pairing subtleties revealed by the effects of different tRNAs on programmed translational bypassing where anticodon re-pairing to mRNA is separated from dissociation. J Mol Biol 345: 39-49.

Burke-Aguero DH, Hearst JE. 1990. An RNA Holliday junction? Structural and dynamic considerations of the bacteriophage T4 gene 60 interruption. J Mol Biol 213: 199-201.

Choi KM, Brimacombe R. 1998. The path of the growing peptide chain through the $23 \mathrm{~S}$ rRNA in the 50S ribosomal subunit; a comparative cross-linking study with three different peptide families. Nucleic Acids Res 26: 887-895.

Choi KM, Atkins JF, Gesteland RF, Brimacombe R. 1998. Flexibility of the nascent polypeptide chain within the ribosome-Contacts from the peptide N-terminus to a specific region of the $30 \mathrm{~S}$ subunit. Eur J Biochem 255: 409-413.
Chou MY, Chang KY. 2010. An intermolecular RNA triplex provides insight into structural determinants for the pseudoknot stimulator of -1 ribosomal frameshifting. Nucleic Acids Res 38: 1676-1685.

Chung BY, Firth AE, Atkins JF. 2010. Frameshifting in alphaviruses: A diversity of 3' stimulatory structures. J Mol Biol 397: 448-456.

Cresawn SG, Bogel M, Day N, Jacobs-Sera D, Hendrix RW, Hatfull GF. 2011. Phamerator: A bioinformatic tool for comparative bacteriophage genomics. BMC Bioinformatics 12: 395.

Culver GM. 2001. Meanderings of the mRNA through the ribosome. Structure 9: 751-758.

Edgell DR, Gibb EA, Belfort M. 2010. Mobile DNA elements in T4 and related phages. Virol J 7: 290.

Ennifar E, Nikulin A, Tishchenko S, Serganov A, Nevskaya N, Garber M, Ehresmann B, Ehresmann C, Nikonov S, Dumas P. 2000. The crystal structure of UUCG tetraloop. J Mol Biol 304: 35-42.

Farabaugh PJ. 1996. Programmed translational frameshifting. Microbiol Rev 60: 103-134.

Firth AE, Brierley I. 2012. Non-canonical translation in RNA viruses. J Gen Virol 93: 1385-1409.

Gallant JA, Lindsley D. 1998. Ribosomes can slide over and beyond "hungry" codons, resuming protein chain elongation many nucleotides downstream. Proc Natl Acad Sci 95: 13771-13776.

Gherghe CM, Mortimer SA, Krahn JM, Thompson NL, Weeks KM. 2008. Slow conformational dynamics at $\mathrm{C} 2^{\prime}$-endo nucleotides in RNA. J Am Chem Soc 130: 8884-8885.

Gherghe C, Lombo T, Leonard CW, Datta SA, Bess JW Jr, Gorelick RJ, Rein A, Weeks KM. 2010. Definition of a high-affinity Gag recognition structure mediating packaging of a retroviral RNA genome. Proc Natl Acad Sci 107: 19248-19253.

Giedroc DP, Cornish PV. 2009. Frameshifting RNA pseudoknots: Structure and mechanism. Virus Res 139: 193-208.

Hargittai MR, Musier-Forsyth K. 2000. Use of terbium as a probe of tRNA tertiary structure and folding. RNA 6: 1672-1680.

Harris DA, Walter NG. 2003. Probing RNA structure and metal-binding sites using terbium(III) footprinting. Curr Protoc Nucleic Acid Chem Chapter 6: Unit 6.8. doi: 10.1002/0471142700.nc0608s13.

Harris DA, Walter NG. 2005. Terbium(III) Footprinting as a probe of RNA structure and metal-binding sites. In Handbook of RNA biochemistry (ed. RK Hartmann, et al.), pp. 205-213. Wiley-VCH, Weinheim.

Harris DA, Tinsley RA, Walter NG. 2004. Terbium-mediated footprinting probes a catalytic conformational switch in the antigenomic hepatitis delta virus ribozyme. J Mol Biol 341: 389-403.

Hatfull GF. 2008. Bacteriophage genomics. Curr Opin Microbiol 11: $447-453$.

Herr AJ, Atkins JF, Gesteland RF. 2000a. Coupling of open reading frames by translational bypassing. Annu Rev Biochem 69: 343-372.

Herr AJ, Gesteland RF, Atkins JF. 2000b. One protein from two open reading frames: Mechanism of a $50 \mathrm{nt}$ translational bypass. EMBO J 19: 2671-2680.

Herr AJ, Wills NM, Nelson CC, Gesteland RF, Atkins JF. 2001. Drop-off during ribosome hopping. J Mol Biol 311: 445-452.

Huang WM, Ao SZ, Casjens S, Orlandi R, Zeikus R, Weiss R, Winge D, Fang M. 1988. A persistent untranslated sequence within bacteriophage T4 DNA topoisomerase gene 60. Science 239: 1005-1012.

Jeong S, Sefcikova J, Tinsley RA, Rueda D, Walter NG. 2003. Trans-acting hepatitis delta virus ribozyme: Catalytic core and global structure are dependent on the $5^{\prime}$ substrate sequence. Biochemistry 42: $7727-7740$.

Kigawa T, Yabuki T, Matsuda N, Matsuda T, Nakajima R, Tanaka A, Yokoyama S. 2004. Preparation of Escherichia coli cell extract for highly productive cell-free protein expression. J Struct Funct Genomics 5: 63-68.

Kladwang W, VanLang CC, Cordero P, Das R. 2011. Understanding the errors of SHAPE-directed RNA structure modeling. Biochemistry 50: 8049-8056.

Kontos H, Napthine S, Brierley I. 2001. Ribosomal pausing at a frameshifter RNA pseudoknot is sensitive to reading phase but shows little correlation with frameshift efficiency. Mol Cell Biol 21: 86578670 . 
Laponogov I, Pan XS, Veselkov DA, McAuley KE, Fisher LM, Sanderson MR. 2010. Structural basis of gate-DNA breakage and resealing by type II topoisomerases. PLoS One 5: el1338.

Larsen B, Peden J, Matsufuji S, Matsufuji T, Brady K, Maldonado R, Wills NM, Fayet O, Atkins JF, Gesteland RF. 1995. Upstream stimulators for recoding. Biochem Cell Biol 73: 1123-1129.

Le SY, Chen JH, Maizel JV Jr. 1993. Identification of unusual RNA folding patterns encoded by bacteriophage T4 gene 60. Gene 124: 21-28.

Legiewicz M, Zolotukhin AS, Pilkington GR, Purzycka KJ, Mitchell M, Uranishi H, Bear J, Pavlakis GN, Le Grice SF, Felber BK. 2010. The RNA transport element of the murine musD retrotransposon requires long-range intramolecular interactions for function. $J$ Biol Chem 285: 42097-42104.

Li GW, Oh E, Weissman JS. 2012. The anti-Shine-Dalgarno sequence drives translational pausing and codon choice in bacteria. Nature 484: 538-541.

Lovett PS. 1994. Nascent peptide regulation of translation. J Bacteriol 176: 6415-6417.

Low JT, Weeks KM. 2010. SHAPE-directed RNA secondary structure prediction. Methods 52: 150-158.

Maldonado R, Herr AJ. 1998. Efficiency of T4 gene 60 translational bypassing. J Bacteriol 180: 1822-1830.

Mazauric MH, Seol Y, Yoshizawa S, Visscher K, Fourmy D. 2009. Interaction of the HIV-1 frameshift signal with the ribosome. Nucleic Acids Res 37: 7654-7664.

McGinnis JL, Dunkle JA, Cate JH, Weeks KM. 2012. The mechanisms of RNA SHAPE chemistry. J Am Chem Soc 134: 6617-6624.

Mortimer SA, Weeks KM. 2007. A fast-acting reagent for accurate analysis of RNA secondary and tertiary structure by SHAPE chemistry. J Am Chem Soc 129: 4144-4145.

Mortimer SA, Weeks KM. 2008. Time-resolved RNA SHAPE chemistry. J Am Chem Soc 130: 16178-16180.

Newby Lambert M, Vocker E, Blumberg S, Redemann S, Gajraj A, Meiners JC, Walter NG. 2006. $\mathrm{Mg}^{2+}$-induced compaction of single RNA molecules monitored by tethered particle microscopy. Biophys J 90: 3672-3685.

Pratt JM. 1984. Coupled transcription-translation in prokaryotic cell-free systems. IRL Press, New York.

Repoila F, Tetart F, Bouet JY, Krisch HM. 1994. Genomic polymorphism in the T-even bacteriophages. EMBO J 13: 4181-4192.

Reuter JS, Mathews DH. 2010. RNAstructure: Software for RNA secondary structure prediction and analysis. BMC Bioinformatics 11: 129.

Ringquist S, MacDonald M, Gibson T, Gold L. 1993. Nature of the ribosomal mRNA track: Analysis of ribosome-binding sites containing different sequences and secondary structures. Biochemistry 32: 10254-10262.
Sefcikova J, Krasovska MV, Spackova N, Sponer J, Walter NG. 2007a. Impact of an extruded nucleotide on cleavage activity and dynamic catalytic core conformation of the hepatitis delta virus ribozyme. Biopolymers 85: 392-406.

Sefcikova J, Krasovska MV, Sponer J, Walter NG. 2007b. The genomic HDV ribozyme utilizes a previously unnoticed U-turn motif to accomplish fast site-specific catalysis. Nucleic Acids Res 35: 1933-1946.

Seol Y, Skinner GM, Visscher K, Buhot A, Halperin A. 2007. Stretching of homopolymeric RNA reveals single-stranded helices and basestacking. Phys Rev Lett 98: 158103.

Sissi C, Palumbo M. 2009. Effects of magnesium and related divalent metal ions in topoisomerase structure and function. Nucleic Acids Res 37: 702-711.

Steen KA, Rice GM, Weeks KM. 2012. Fingerprinting noncanonical and tertiary RNA structures by differential SHAPE reactivity. J Am Chem Soc 134: 13160-13163.

Uzan M, Miller ES. 2010. Post-transcriptional control by bacteriophage T4: mRNA decay and inhibition of translation initiation. Virol J 7: 360.

Vasa SM, Guex N, Wilkinson KA, Weeks KM, Giddings MC. 2008. ShapeFinder: A software system for high-throughput quantitative analysis of nucleic acid reactivity information resolved by capillary electrophoresis. RNA 14: 1979-1990.

Walter NG, Yang N, Burke JM. 2000. Probing non-selective cation binding in the hairpin ribozyme with $\mathrm{Tb}$ (III). J Mol Biol 298: 539-555.

Watts JM, Dang KK, Gorelick RJ, Leonard CW, Bess JW Jr, Swanstrom R, Burch CL, Weeks KM. 2009. Architecture and secondary structure of an entire HIV-1 RNA genome. Nature 460: 711-716.

Weiss RB, Huang WM, Dunn DM. 1990. A nascent peptide is required for ribosomal bypass of the coding gap in bacteriophage T4 gene 60 . Cell 62: 117-126.

Wilkinson KA, Gorelick RJ, Vasa SM, Guex N, Rein A, Mathews DH, Giddings MC, Weeks KM. 2008. High-throughput SHAPE analysis reveals structures in HIV-1 genomic RNA strongly conserved across distinct biological states. PLoS Biol 6: e96.

Wilkinson KA, Vasa SM, Deigan KE, Mortimer SA, Giddings MC, Weeks KM. 2009. Influence of nucleotide identity on ribose $2^{\prime}$-hydroxyl reactivity in RNA. RNA 15: 1314-1321.

Wills NM, O'Connor M, Nelson CC, Rettberg CC, Huang WM, Gesteland RF, Atkins JF. 2008. Translational bypassing without peptidyl-tRNA anticodon scanning of coding gap mRNA. EMBO J 27: 2533-2544.

Woodson SA. 2001. Probing RNA folding pathways by RNA fingerprinting. Curr Protoc Nucleic Acid Chem Chapter 11: Unit 11.4. doi: 10.1002/047114270.nc1104s02.

Yusupova GZ, Yusupov MM, Cate JH, Noller HF. 2001. The path of messenger RNA through the ribosome. Cell 106: 233-241. 

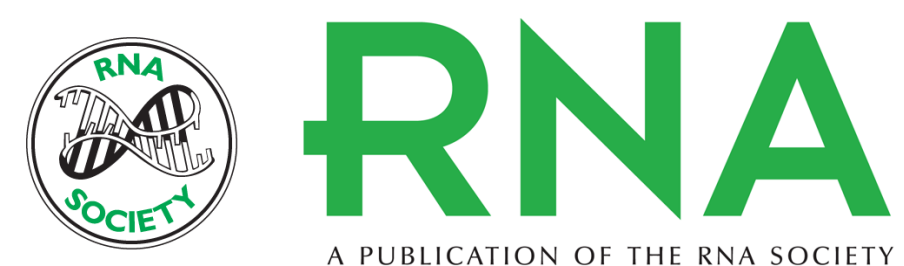

A PUBLICATION OF THE RNA SOCIETY

\title{
Secondary structure of bacteriophage T4 gene 60 mRNA: Implications for translational bypassing
}

\author{
Gabrielle C. Todd and Nils G. Walter
}

RNA 2013 19: 685-700 originally published online March 14, 2013

Access the most recent version at doi:10.1261/rna.037291.112

\section{References This article cites 60 articles, 13 of which can be accessed free at: http://rnajournal.cshlp.org/content/19/5/685.full.html\#ref-list-1}

\section{License}
Email Alerting Receive free email alerts when new articles cite this article - sign up in the box at the Service top right corner of the article or click here.

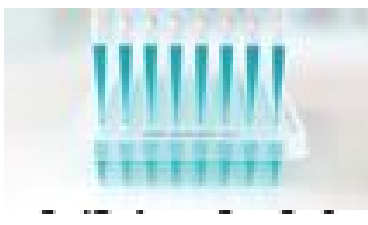

\section{Providing Precise Solutions for} your research.

To subscribe to $R N A$ go to:

http://rnajournal.cshlp.org/subscriptions 